\title{
LAS FUENTES DE CLEM. ALEX., PROTR. II 12-22: UN TRATADO SOBRE LOS MISTERIOS Y UNA TEOGONÍA ÓRFICA.
}

Miguel HerRero de JÁUREGUI Alma Mater Studiorum- Università degli Studi di Bologna

\begin{abstract}
Los ataques contra los misterios griegos que lanza Clemente de Alejandría en Protr. II 12-22 son una fuente principal de conocimiento de los cultos mistéricos, especialmente de Dioniso y Deméter. La idea errónea de que Clemente los conocía por propia experiencia ha impedido hasta ahora el estudio en profundidad de sus fuentes librescas: un tratado sobre los misterios que a su vez toma como base un poema órfico. Este estudio trata de establecer el contenido mitográfico y ritual del tratado y del poema; fija su origen y datación aproximados; e indaga las relaciones del texto clementino con otros testimonios helenísticos y tardoantiguos.
\end{abstract}

Palabras clave: Clemente de Alejandría, misterios, orfismo, Papiro de Gurob.
The accusations against Greek mysteries made by Clement of Alexandria in Protr. II 12-22 are a main source for our knowledge of ancient mystery cults, specially those of Dionysus and Demeter. The mistaken assumption that Clement knew them through his own experience has hitherto prevented a thorough study of his bookish sources: a treatise on mysteries which is itself based on an Orphic poem. This paper aims to establish the mythographical and ritual contents of the treatise and the poem; it fixes their approximate origin and date of composition; and it examines the relations of Clement's text with other evidence from Hellenistic Age and Late Antiquity.

Keywords: Clement of Alexandria, mysteries, Orphism, Gurob Papyrus.

\section{El ataque a los misterios en Protréptico II 12-22}

Clemente de Alejandría inicia su Protréptico con una invitación a seguir el canto nuevo de su Logos abandonando el de Orfeo. El canto engañoso del poeta tracio que arrastra con su música es, en la interpretación del alejandrino, el culto de los misterios griegos, que deben ser sustituidos por los verdaderos misterios de Cristo. Según las reglas de la retórica que guían el género exhortativo, al exordium sigue la refutatio de la posición rival ${ }^{1}$. Así, el libro II empieza con un breve ataque contra los oráculos (II 11), al que sigue una feroz diatriba contra los misterios griegos (II 12-22): todos ellos en general, y los de Afrodita, Cibele, Dioniso, los Cabiros y Eleusis en particular.

Sobre el protréptico como género filosófico y literario, cf. Van der Meeren 2002; para su aplicación apologética en Clemente, cf. Van der Hoek 2005. 
El texto es de una importancia capital para la comprensión del orfismo, de los misterios y de la religión griega en general, pues ofrece gran cantidad de información original y muchos detalles no transmitidos en ninguna otra fuente sobre un mundo en el que la cantidad de problemas por aclarar es proporcional al interés que despierta. El significado de diversas alusiones míticas y rituales es aún oscuro (probablemente lo era ya para el propio Clemente) y muchos puntos particulares son objeto de discusión. Falta, sin embargo, una investigación a fondo del origen de toda esta información transmitida por Clemente $^{2}$, una laguna que este estudio pretende llenar. Se examinarán también sus relaciones con otros textos griegos y latinos, algunos de los cuales ofrecen datos coincidentes o complementarios. La extensión del texto imposibilita editarlo aquí, por lo que aconsejo su lectura previa para seguir mejor la Quellenforschung.

\section{2. ¿Conocimiento directo o fuente libresca?}

Si estos pasajes del Protréptico han sido tan frecuentemente citados como poco investigados es porque aún tiene mucho peso la idea, durante largo tiempo incontestada, de que Clemente conocía los misterios de primera mano porque había sido iniciado en ellos antes de su conversión al cristianismo. El único que transmite esta noticia es Eusebio ( $P E$ II 2.64), que cuando recoge el texto de Clemente 150 años más tarde, lo introduce con la siguiente afirmación:

Esto desvela a las claras el admirable Clemente en el Protréptico a los griegos, un hombre que había pasado por todos y que rechazó rápidamente el error ( $\pi \alpha ́ v \tau \omega v \mu \grave{\varepsilon} v$

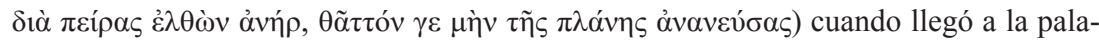
bra salvadora y se redimió de los males gracias a la doctrina evangélica.

Esta noticia de Eusebio es sospechosa. En primer lugar, Clemente mismo no hace la menor mención de su iniciación en toda su obra. Además, responde a un topos de la época: hay mayor autoridad para pregonar la verdad cuando se han probado todos los errores y se testifica contra ellos con la propia experiencia como prueba. Justino (Apologia) o Agustín (Confesiones) son ejemplos célebres. En estos casos la experiencia de conversión es cierta, pero precisamente algunos casos ciertos son los que provocan la extensión de un

2 Riedweg 1987 y Robertson 1996 son los únicos que han indagado sobre la fuente de Clemente (cf. n.3). El texto es riquísimo en detalles que merecen un análisis profundo. Este artículo se enmarca dentro de un proyecto más amplio de comentario del Protréptico, que no existe aún en ninguna lengua.

EMERITA (EM) LXXV 1, enero-junio $2007 \quad$ pp. 19-50 ISSN 0013-6662 
lugar común. Y el párrafo de Eusebio tiene la clara intención de reforzar la autoridad de la descripción de los misterios que sigue.

Si ya estas razones hacen dudar de una iniciación personal de Clemente en los misterios, Ch. Riedweg ofrece además una serie de argumentos convincentes para pensar en una fuente escrita, un tratado pagano sobre los misterios ${ }^{3}$ :

1) La sección está ordenada conceptualmente: etimologías (II 12-13.2), fundadores (II 13.3-5) y presentación de cada misterio (II 14-22), siguiendo la estructura mito-ritual: un relato mítico y después los $\sigma 0 ́ \mu \beta 0 \lambda \alpha$ o $\sigma v v \theta \eta \dot{\mu} \mu \alpha \tau \alpha$ que lo conmemoran ${ }^{4}$.

2) Los misterios se ordenan alfabéticamente: Afrodita-Deo-Dioniso-CoribantesCore o Feréfata (fuera cual fuera el lema, con $\kappa$ o con $\varphi$, tendría el último lugar en orden alfabético). El orden conceptual y alfabético apuntan a un origen libresco más que al recuerdo espontáneo de la propia experiencia.

3) Fuera de este pasaje, Clemente no hace referencia a estos misterios en ninguna de sus obras, aparte de alusiones más generales a las Bacantes o a Eleusis, que son perfectamente atribuibles a su amplia cultura, y no a una iniciación anterior. Si en el resto de su obra no vuelve a dar detalles específicos, es probablemente porque no usa ya este tratado ${ }^{5}$.

4) Clemente parece mostrar la típica actitud del no iniciado que no entiende bien los $\sigma u ́ \mu \beta 0 \lambda \alpha$ de los iniciados, pese a sus intentos de ridiculizarlos.

3 Riedweg 1987, pp. 117-123. En p. 120 n. 23, cita a sus escasos predecesores (Lobeck, Diels) en su escepticismo sobre la noticia de Eusebio, los cuales, sin embargo, no indagaron en la fuente de Clemente. Robertson 1996, pp. 365-375 habla de la fuente, pero no añade nada sustancial a Riedweg. La considera un glosario transmitido por Dídimo para facilitar la comprensión de la literatura clásica, pero no aporta ninguna prueba que apoye tal suposición. Mora 1994, pp. 70-73 niega que fuera un tratado y la reduce a "fuente mitográfica" reciente a la que Clemente habría añadido los elementos rituales. Pero esta tesis, que elabora para defender su difícil idea de que Arnobio no depende de Clemente, tiene muchos datos en contra y pocos a favor (cf. n.59).

4 La función de $\sigma u ́ \mu \beta o \lambda \alpha$ y $\sigma v v \theta \eta ́ \mu \alpha \tau \alpha$, tanto verbales como físicos, es recordar la experiencia iniciática: sólo el iniciado entiende su significado, que puede parecer oscuro o banal al resto (Burkert 1987, pp. 45-47).

5 El estudio de Van der Hoek 1996 sobre las técnicas de cita de Clemente refuerzan esta idea. El sistema de copiar las notas tomadas de un rollo de papiro (o el rollo mismo) en una sección determinada y dejarlas de lado después de acabar la sección corresponde a lo que hace aquí. Cf. Protr. II 39.1: “¿no reconocéis a vuestros propios autores que pongo como testigos de vuestra impiedad?”. Mora 1994, pp. 70-73 niega que estas pruebas de Riedweg demuestren el origen libresco, pero el orden alfabético difícilmente puede ser casual.

EMERITA (EM) LXXV 1, enero-junio $2007 \quad$ pp. 19-50 ISSN 0013-6662 
A los argumentos de Riedweg aún se pueden añadir otros:

5) Clemente describe misterios de Chipre (Afrodita), Frigia (Deo) y Atenas. ¿No es difícil suponer que antes de recalar en Alejandría hubiera viajado iniciándose en todos estos misterios sin dar noticia alguna de ello?

6) Clemente incurre en algunas inexactitudes flagrantes que proceden de un resumen apresurado de su fuente, como cuando dice que los cerdos de Eubúleo son tragados junto con las dos diosas ( $\tau \alpha i$ iv $\theta \varepsilon \alpha i i v)$ en el rapto de Core (17.1).

7) El orden del relato no es sólo alfabético y sistemático, sino también cronológico: los mitos fundacionales de los diferentes misterios siguen un orden generacional (Afrodita nace de la castración de Urano, Deméter violada por Zeus da a luz a Perséfone que, violada por Zeus, da a luz a Dioniso, que es desmembrado por los Titanes y cuyo falo es origen de los misterios cabíricos; el relato acaba con la búsqueda de Deméter de su hija Perséfone). Este orden teogónico hace pensar en un poema que subyace al relato de Clemente $-\mathrm{y}$ al del tratado que constituye su fuente directa- y del que provienen los versos de Orfeo citados al hilo del relato.

Conviene detenerse aquí un momento, porque la investigación de este poema teogónico órfico es un elemento central de este artículo. Orfeo no sólo aparece como instructor de Midas para la fundación de los misterios frigios (II 13.3) y como poeta y mistagogo de los misterios de Dioniso (II 17.2-18) y Deméter (II 21). Además, las narraciones míticas de los demás misterios coinciden con el contenido de la tradición órfica que conocemos por otras fuentes: sin duda se atribuía a Orfeo el poema en que se basa el tratado. Todo el texto de Clemente, cuya información detallada sobre los misterios griegos provenía sobre todo de este tratado, constituye una unidad de "fuerte tinte órfico" ${ }^{6}$, por lo que no es extraño que hiciera a Orfeo el cantor de los misterios paganos, contraponiéndolo al canto del Logos, el del verdadero misterio cristiano. Clemente presenta los misterios como una sola superstición, un conjunto impío de "muertes y tumbas"7. Pero al unificar los misterios en un solo ente el alejandrino sigue la tendencia de sus fuentes, que ya desarrollaban una visión

6 Riedweg 1987, p. 117: “stark orphisch geprägt”. Gran parte del texto está disperso en la edición de los Orphica de Alberto Bernabé (2004), que se cita aquí como OF. Agradezco al autor que me permitiera usar su edición mucho antes de su publicación y su paciente guía por los entresijos del orfismo.

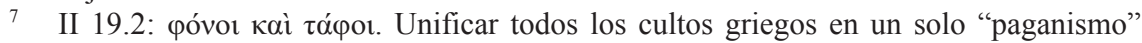
(Scarpi 2001, pp. XXIV-XXV) construido como ente simétrico y opuesto al cristianismo es consustancial a la imagen de la conversión como viaje de un campo al otro que impregna el Protréptico. Cf. Herrero 2005. 
conjunta de los diversos cultos al presentarlos conjuntamente, en forma sistemática (el tratado) y cronológica (el poema). Los dioses de varios misterios, siguiendo una tendencia que ya encontramos en el Papiro de Derveni ${ }^{8}$, se identifican entre sí, (p. e. la epiclesis Deó reúne a Cibele, Deméter y Rea), y los $\sigma 0 ́ \mu \beta о \lambda \alpha$ y $\sigma v v \theta \eta \dot{\eta} \mu \alpha \tau \alpha$ de cultos diferentes son muy parecidos ${ }^{9}$.

Algunas de las semejanzas entre los cultos pueden ser casuales, fruto de la descripción conjunta de lo que naturalmente se parece, pero en su mayoría son buscadas y resaltadas a propósito. El objetivo unificador es compartido, aunque por diversos motivos, por Clemente, por su fuente inmediata (el tratado) y por su fuente lejana (el poema órfico). Que los diversos autores que usan la información mitográfica tengan la misma orientación favorece que transmitan el material previo, pero a su vez dificulta distinguir qué toman de sus fuentes anteriores y qué es añadido o alterado por cada uno. Por ello la labor de Quellenforschung es especialmente complicada. Es imposible alcanzar absoluta certeza, pero se puede tratar de fijar aproximadamente el contenido de cada estrato. Aparte del análisis filológico interno, hay por fortuna un testimonio externo de gran valor que conviene analizar previamente: el Papiro de Gurob.

\section{El texto de Clemente y el Papiro de Gurob}

Acabamos de comprobar en el texto de Clemente y en sus fuentes una tendencia a la unificación, en parte buscada y en parte natural, de los misterios griegos. En el $P$. Gurob, datado en torno al 275 a. C. ${ }^{10}$, se observa un fenó

8 En P. Derv. col XXII.7 (OF 398) el comentarista cita el siguiente verso de los Him-

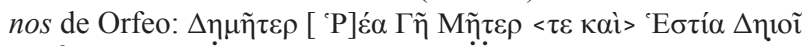

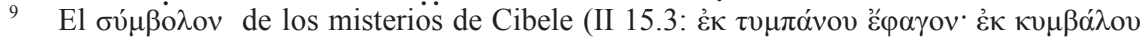

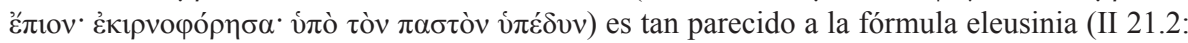

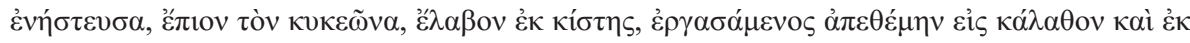

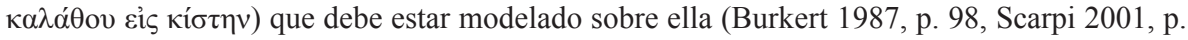

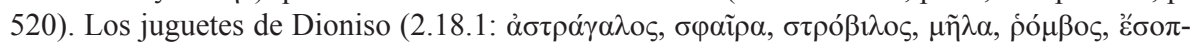

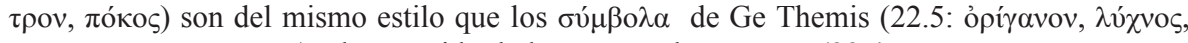

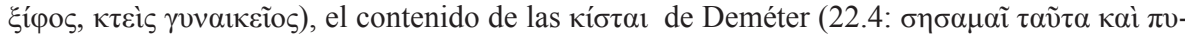

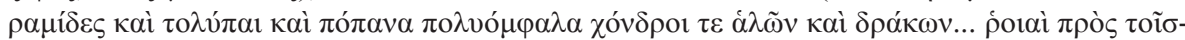

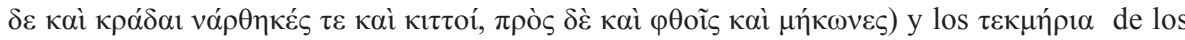

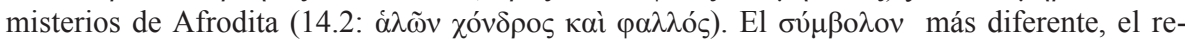

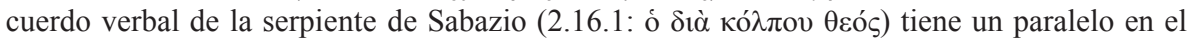
ofidio de las cestas de Deméter (22.4).

10 OF 578: editado de nuevo por Hordern 2000, con toda la bibliografía. Cf. los comen-

EMERITA (EM) LXXV 1, enero-junio $2007 \quad$ pp. 19-50 ISSN 0013-6662 
meno muy similar: se menciona e invoca a diferentes divinidades al mismo tiempo como parte del mismo culto. El papiro parece contener instrucciones para la celebración de un culto sincrético de diversos misterios en el que se observan elementos báquicos, órficos y eleusinios: menciona un sacrificio con carne cruda y cocida, presenta diversas invocaciones rituales, algunas de ellas en verso, y acaba con una serie de fórmulas muy similares a los $\sigma v ́ \mu \beta o-$ $\lambda \alpha$ descritos por Clemente y la mención de unos objetos que son indudablemente los juguetes de Dioniso. El siguiente cuadro pone de relieve el asombroso paralelo de estos dos textos, separados por cinco siglos, que no puede ser casual:

\begin{tabular}{|c|c|c|}
\hline & P. Gurob 1. & Clem. Alex., Protr. II 12-22 \\
\hline \multirow[t]{5}{*}{$\begin{array}{l}\text { divinidades } \\
\text { celebradas }\end{array}$} & 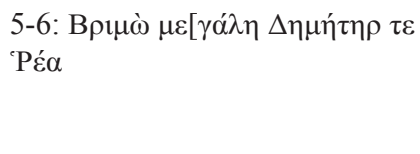 & 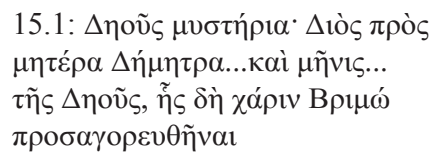 \\
\hline & 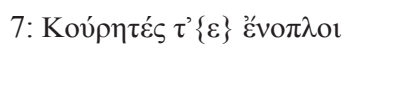 & 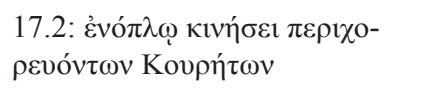 \\
\hline & 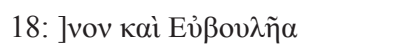 & 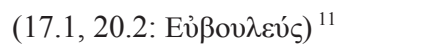 \\
\hline & 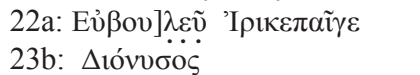 & 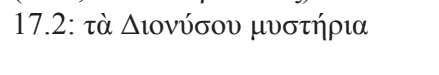 \\
\hline & 21: $\Delta] \eta \dot{\mu} \mu \eta \tau \rho о \varsigma \kappa \alpha \grave{~} \Pi \alpha \lambda \lambda \alpha \dot{\delta} \delta \varsigma$ & 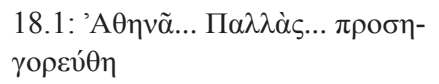 \\
\hline \multirow[t]{4}{*}{ fórmulas rituales } & 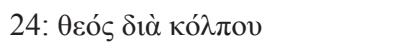 & 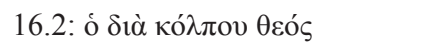 \\
\hline & 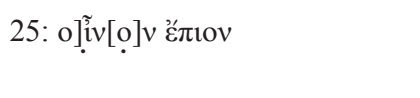 & 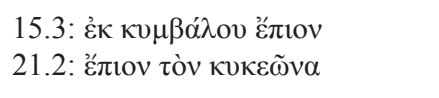 \\
\hline & 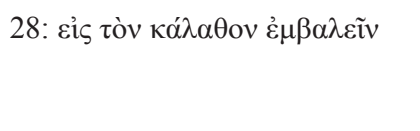 & 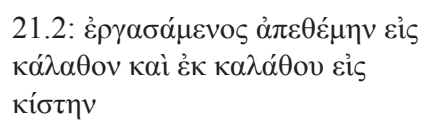 \\
\hline & & 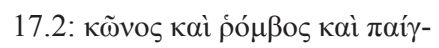 \\
\hline
\end{tabular}

tarios de West 1983, pp. 169-174. Henrichs 2003 lo considera el ejemplo más directo de un

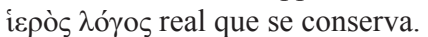

11 El Eubuleo del papiro tiene visos de ser el dios (Dioniso) invocado en las laminillas de Turios ( $O F$ 488-490), y no el humilde porquero del relato órfico-eleusinio transmitido por Clemente.

EMERITA (EM) LXXV 1, enero-junio $2007 \quad$ pp. 19-50 ISSN 0013-6662 


\begin{tabular}{|c|c|c|}
\hline & 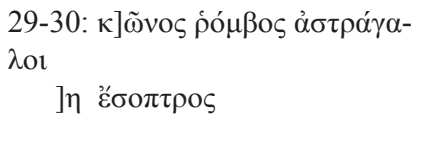 & 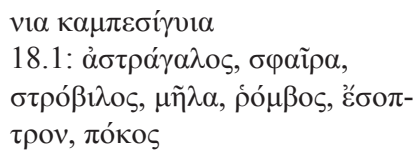 \\
\hline palabras técnicas & 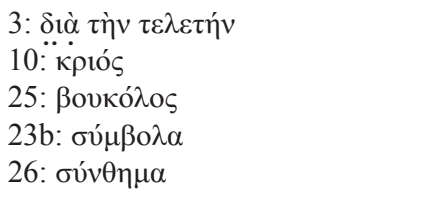 & 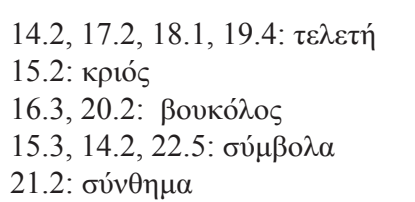 \\
\hline
\end{tabular}

En el cuadro se puede percibir que los paralelos de ambos textos siguen generalmente el mismo orden, es decir, como si la disposición del relato clementino coincidiera a grandes rasgos con el del ritual descrito por el papiro.

La mayoría de estas concordancias son tan claras que se reconocieron desde el descubrimiento del papiro, $\mathrm{y}$ ha sido generalmente aceptado que, aunque el nombre de Orfeo no aparece en la parte conservada, éste pertenece al ámbito órfico, no ya sólo por sus correspondencias con el texto de Clemente, sino también por sus coincidencias con otros testimonios específicamente órfi$\cos ^{12}$. Por eso varios estudiosos han tratado de llenar lagunas del papiro con conjeturas derivadas, no sólo del texto de Clemente, sino también de otros fragmentos órficos, y en mi opinión aún cabe avanzar un poco en esta línea ${ }^{13}$.

12 P. e. los sobrenombres para Dioniso en la línea 22 de Ericepeo $(O F$ 162) y Eubuleo (OF 488) o la invocación en la línea 23 b de eís $\Delta$ tóvvбos (OF 543).

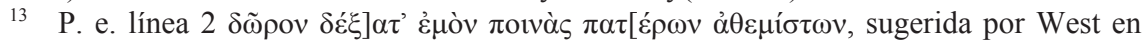

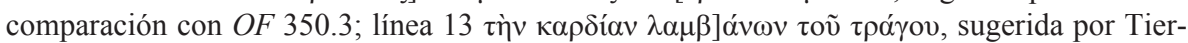

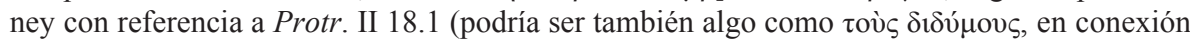

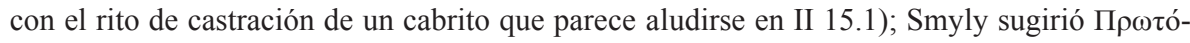
yo]vov para la línea 18 (también cabría $\alpha \gamma]$ vóv como propone West, e incluso me atrevo a su-

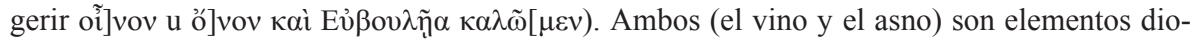
nisiacos (cf. Iust.Phil., Apol. 1.54, Dial. 69) que encajarían perfectamente con el espacio paleográfico y el contenido del papiro. Sugiero también la restitución siguiente para la línea 24:

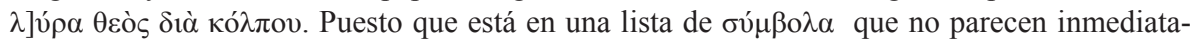
mente relacionados entre sí, la lira, aparte de encajar con las letras conservadas, podría tener su cabida lógica como elemento órfico en una mezcla de elementos tan dispares. Sería la única alusión casi directa a Orfeo mismo en el papiro, y además encajaría con la ocasional presencia, con connotaciones escatológicas, de la lira en los misterios (cf. Hardie 2004). Recordemos además la música de Orfeo-Cristo en Protr. I 1.5, que podía inspirarse en alguna presencia de elementos musicales en su fuente sobre los misterios. Cf. Eizenhofer 1960 sobre el origen pagano de la lira como símbolo cristiano propuesto por Clemente en Paed. 3.11.

EMERITA (EM) LXXV 1, enero-junio 2007 pp. 19-50 ISSN 0013-6662 
Pero más allá de la especulación papirológica, la relación entre ambos textos no se ha explotado de la manera que parece más natural, para recabar más información sobre la fuente de Clemente. Es claro que no debe postularse una relación directa entre el papiro y ésta, pero las estrechas semejanzas apuntan a un contexto no muy distinto para el origen del papiro y de la fuente de Clemente. El P. Gurob corrobora que la unificación de cultos mistéricos era una tendencia muy anterior a Clemente; ofrece un significativo material para determinar el contenido de las fuentes que subyacen al pasaje clementino y su anclaje en la realidad cultual; y supone además un punto de referencia para indagar la datación y el origen de estas fuentes. De todo ello se trata de sacar provecho en los puntos siguientes.

\section{Estratos del material mitográfico}

Cinco siglos median entre el P. Gurob y el Protréptico. Aparte de la elaboración de Clemente, pueden distinguirse dos estratos que cubren esta distancia temporal: el tratado sobre los misterios (abreviado a partir de ahora como TM), y la teogonía órfica de la que provienen los versos citados, que obviamente es anterior al tratado (abreviada a partir de ahora como $\mathrm{Tg}$ ). Es posible que hubiera eslabones intermedios: poemas que se compusieran a partir de otros, resúmenes del tratado que lo reorganizaran, o incluso, puestos a imaginar, que Clemente tomara toda esta información de otro apologista judío o cristiano que a su vez usara el tratado. Pero si ha habido eslabones intermedios, no han dejado ninguna huella reconocible, y hay que ceñirse a las tres etapas que se pueden detectar: la teogonía, el tratado, y el propio Clemente. Trataré ahora de distinguir en lo posible qué partes de la información transmitida en el texto corresponden a cada estrato, empezando por los más tardíos, es decir, los añadidos por el propio Clemente a su fuente. Como toda labor analítica basada en evidencia interna, es claro que se expone a cierta subjetividad e incertidumbre. Intentaré dejar claro qué partes son más especulativas e inciertas que otras.

\section{1. ¿Qué añade y qué conserva Clemente?}

Puede eliminarse de los estratos más antiguos lo añadido por Clemente a $T M$. Es lícito sospechar que el apologista ha insertado todo aquello que favorece su propósito polémico antipagano pero que no encaja con la estructura ni objetivos de su fuente. Deben de provenir de Clemente las burlas que no

EMERITA (EM) LXXV 1, enero-junio $2007 \quad$ pp. 19-50 ISSN 0013-6662 
ofrecen información nueva y todo lo que en general da a la sección su forma retórica de refutatio. La metáfora de presentar los diversos mitos como piezas concursantes en un agón teatral del que el drama cristiano sale vencedor ha creado cierta confusión al tomarse como prueba de una representación teatral en Eleusis, claro ejemplo de la distorsión que las fuentes cristianas pueden producir al presentar los cultos griegos ${ }^{14}$. Lo más difícil de calibrar es la proveniencia del material mitográfico.

El problema más obvio se presenta al final de la sección. Clemente parece dejar de seguir a $T M$ tras revelar el $\sigma 0 ́ v \theta \eta \mu \alpha$ de Eleusis en 22.1: a continuación, una cita de Heráclito $(22.1-2=$ fr. $14 \mathrm{DK})$, un párrafo inspirado en Filón (22.3= Filón, Cher. 94) y un ataque retórico a los misterios de Eleusis (22.67) tienen un origen claramente distinto de TM. Entre estos dos últimos pasa-

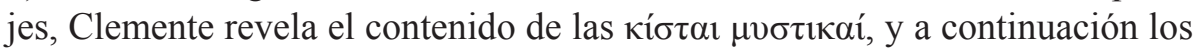
$\sigma u ́ \mu \beta o \lambda \alpha$ de los misterios de $(\mathrm{Ge})$ Themis ${ }^{15}$. Cabe preguntarse si esta lista de objetos rituales proviene de la misma fuente que los $\sigma u ́ \mu \beta o \lambda \alpha$ de los misterios anteriores: insertados entre pasajes de origen y propósito distintos, no hay narración mítica alguna que los justifique, al contrario de lo que ocurría en los misterios anteriores, y al introducir a (Ge) Themis se rompe el orden

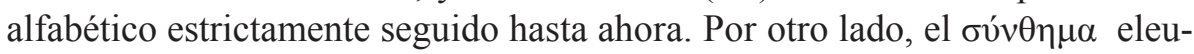

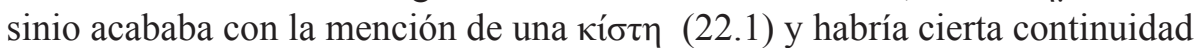

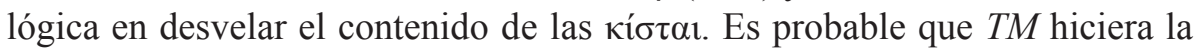
fácil equivalencia, no recogida por Clemente, entre los misterios de Themis y los de Deméter y Core, en línea con otras asimilaciones que Clemente sí menciona (Cibele-Deméter, Dioniso-Atis, Zeus-Sabazio), lo cual salvaría el orden alfabético al incluirlo en la sección de Feréfata-Core. Parece, pues, probable que el pasaje de 22.5-6 provenga de $T M$, aunque Clemente haya insertado

14 Protr. I 2.3, II 12.2. Wilamowitz 1931 II, p. 374 descartó drásticamente que esta metáfora implicara una acción ritual real: "Also weg mit diesen Phantasereien”. Otros testimonios independientes (Tert. Ad Nat. 2.7, Lact. Ep. 23, Arist. Eleus. 19 p. 422 Dindorf, Lucian, Katapl. 22, Hipp., Ref. 5.8.39-40) sí hablan de cierta representación simbólica (no un drama teatral) de la búsqueda de Deméter (cf. Scarpi 2001, p. 517 y Sourvinou-Inwood 2003).

15 El texto preservado por los MSS dice $\tau \tilde{\eta} \varsigma ~ \Theta \varepsilon ́ \mu t \varsigma$, pero ha sido generalmente aceptada

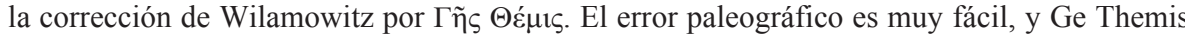
encaja bien, además, con la divinidad principal de los misterios de Flía. Casadio 1997, p. 56s pone el texto en relación con Hippol., Ref. V 20.4, que se refiere a los Bacchica de Orfeo al hablar de los misterios de Flía, y sugiere que Clemente pudo tenerlos presentes. Pero es dudoso si Bacchica se refiere a un libro o a acciones rituales y además la conexión con Flía es la única coincidencia de ambos textos. P. e. Baubo puede relacionarse con la Ficola de Hipólito en el nivel antropológico, no como derivadas de una misma fuente textual común.

EMERITA (EM) LXXV 1, enero-junio $2007 \quad$ pp. 19-50 ISSN 0013-6662 
antes material procedente de otras fuentes.

El añadido mitográfico que parece más evidente, aparte de la etimología del grito báquico eủó a partir de la Eva bíblica (II 12.1), es el personaje de Cíniras como fundador de los misterios de Afrodita para adorar a una prostituta (II 13.4): esta explicación evemerista contradice la narración mítica del nacimiento de Afodita en II 14; su nombre rompe el orden alfabético de los fundadores de misterios en la sección de II 13; y Clemente alude a él en otros pasajes del Protréptico (II 33.9; III 45.4) tomados de otras fuentes con un tono epicúreo-evemerista que no aparece en ningún otro lugar de esta sección. Es muy probable, pues, que Cíniras fuera introducido aquí por Clemente mismo, que lo conocía por otras fuentes de corte evemerista ${ }^{16}$.

La misma explicación puede darse a la cita de Apolodoro, según el cual la etimología de $\mu v \sigma \tau$ ṕpıv viene del cazador ático Myus. La cita permite a Clemente insistir en que los misterios celebran asesinatos, pero rompe la simetría

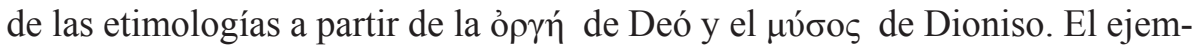
plo confirma que el alejandrino es capaz de introducir detalles procedentes de otras fuentes en una sección en que sigue principalmente una ${ }^{17}$. Por ello, no cabe descartar que ciertos detalles míticos o rituales puedan provenir de otras fuentes consultadas o simplemente recordadas, como el tabú de la granada en las Tesmoforias asociado al apio de los misterios de Samotracia (19.3).

Más difícil es calibrar hasta qué punto Clemente abrevia o expande la narración mitográfica de $T M^{18}$, pero da la impresión de que cuando no hace ex

16 Las sección evemerista sobre Afrodita no procede de Evemero mismo. Winiarczyk 1991, pp. 50-52 coloca las alusiones a la diosa entre los dubia, pero más tarde (Winiarczyk 2002, pp. 16-17) no tendrá dudas en considerarlos falsa. En cualquier caso, sólo serían atribuibles a una fuente evemerista las breves referencias a Cíniras, pues el nacimiento de Afrodita de la castración de Urano pertenecía, con toda probabilidad, a la teogonía órfica.

17 Protr. 2.13.1 = F.Gr.Hist. 244 F103. Clemente cita el Пврі $\theta \varepsilon \tilde{\omega} v$ de Apolodoro también en Protr. 2.29.16, posiblemente a partir de fuentes epicúreas similares a las de Filodemo o Cicerón (Henrichs 1975, pp. 5-7). Sobre las técnicas de utilización de fuentes en Clemente, cf. van der Hoek 1996.

18 Sobre la anticipación del relato en 17.1, cf. n. 24. Es más especulativo suponer qué podía estar en su fuente y Clemente habría omitido porque no se adecuaba a sus necesidades apologéticas: tal vez un eventual relato de la resurrección de Dioniso porque no podía burlarse de la resurrección de un dios (cf. Iust. Phil., Apol.1.54, Dial. 69 que la presenta como pla-

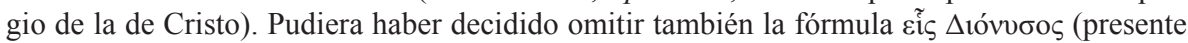
en el $P$. Gurob (23b) y en el $O F$ 543.1), que da la impresión que TM habría aceptado gustosa para sus propósitos dionisocéntricos si la hubiera conocido como $\sigma 0 ́ \mu \beta 0 \lambda o v$, pero que Clemente no podía ridiculizar como los otros $\sigma 0 ́ \mu \beta \mathrm{o} \lambda \alpha$ y $\sigma v v \theta \eta \dot{\mu} \mu \alpha \tau \alpha$, pues es muy similar a los

EMERITA (EM) LXXV 1, enero-junio $2007 \quad$ pp. 19-50 ISSN 0013-6662 
cursos polémicos no se aparta en exceso de ella, aunque escoja explayarse, claro es, en los episodios más escandalosos como el de Baubo. El caso del mito de Dioniso y los Titanes (II 17.2-18.2) es paradigmático: no sólo están los paralelos ya mencionados con el $P$. Gurob, sino que usa palabras idénticas a Diodoro (V 75.4) al contar el episodio ( $\delta 1 \alpha \sigma \pi \alpha ́ \omega, \kappa \alpha \theta \varepsilon \dot{\varepsilon} \psi \omega)$, lo que parece indicar que no modifica en exceso las expresiones de su fuente. Del mismo modo, cuando cuenta que Apolo entierra a Dioniso por orden de Zeus ("'O $\delta \dot{\varepsilon}$,

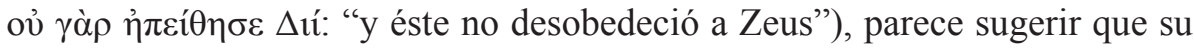
resumen en prosa (o el de su fuente) parafrasea un verso similar, probablemente idéntico, a Il. XVI 677, tras la orden de Zeus a Apolo de enterrar a

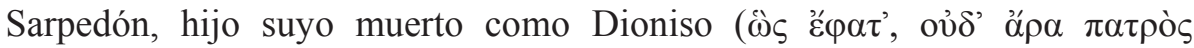

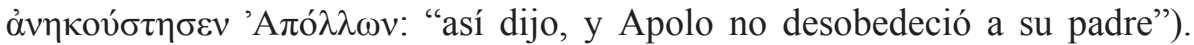
Parece lógico deducir que el poema órfico $(\mathrm{Tg})$ tenía versos muy similares al episodio homérico, recogidos por $T M$, cuyo rastro queda en la prosa clementi-

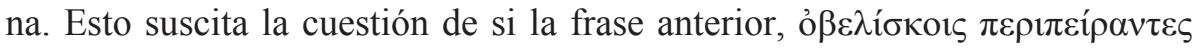

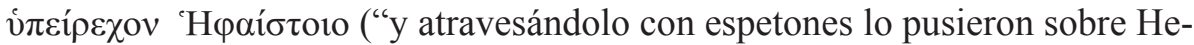
festo") de clara resonancia homérica ${ }^{19}$, proviene de $T g$ o de la imaginación literaria de Clemente. Lo cierto es que la frase no ofrece ningún motivo de burla, de modo que es probable que el verso homérico estuviera en $T g$, en el que el ritual del sacrificio tiene una importancia especial (cf. infra). Por la

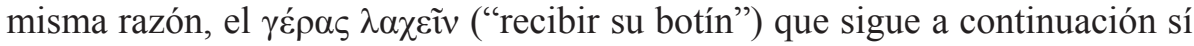
puede proceder de Clemente mismo, pues tiene un tono polémico de burla, aunque no cabe descartar que estuviera en $T g$ como referencia homérica y Clemente (conociéndola siempre a través de $T M$ ) la reutilizara en su propio interés ${ }^{20}$.

Este análisis demuestra que, salvo inserciones puntuales, Clemente guarda

lemas monoteístas y trinitarios cristianos (عĩ $\theta \varepsilon o ́ \varsigma)$. Esta vertiente del orfismo será, en cambio, aprovechada para apoyar el monoteísmo (p. e. en la misma obra Protr. VII 74.3-6). Cf. Herrero 2007, pp. 224-226 y 277-307.

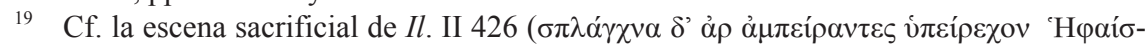

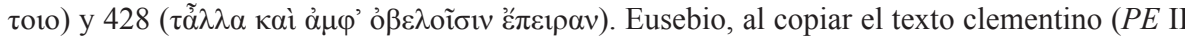
2.65) adapta aún más el verso escribiendo ante $\pi \varepsilon i ́ \rho \alpha v \tau \varepsilon \varsigma$ el prefijo $\alpha \mu$ - en vez de $\pi \varepsilon \rho t-$, métricamente imposible.

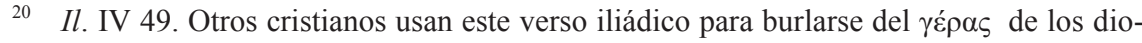
ses paganos (cf. las referencias en el aparato crítico de la edición de West). Sin embargo, Arnobio ( $A d v$. Nat. 5.19) parece hacerlo parte de la narración, lo que apoyaría su presencia en el poema original: "quemadmodum Iuppiter suauitate odoris inlectus, inuocatus advolarit ad prandium”. Sobre la relación del texto de Arnobio con el Protréptico, cf. n. 59.

EMERITA (EM) LXXV 1, enero-junio $2007 \quad$ pp. 19-50 ISSN 0013-6662 
con fidelidad la información transmitida por su fuente ${ }^{21}$. Veamos ahora el contenido de ésta.

\subsection{El tratado sobre los misterios}

La fuente directa de Clemente a partir de 12.1 es un tratado sobre los misterios griegos $(T M)$. Puede descartarse que la sección anterior sobre los oráculos (11.1-3) formara parte de la misma obra, por diferencia de tema y porque no están ordenados alfabéticamente. Además, la introducción de Clemente a su ataque a los misterios (12.1) parece estar tomada de TM: trata de justificar su exposición diciendo que lo prohibido por el secreto era hacer una parodia ( $\dot{\xi} \xi o \rho \chi \eta ́ \sigma \theta \alpha)$, no desvelar los misterios, que no pretende profanar,

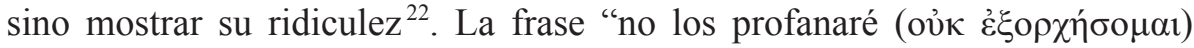
como dicen que hizo Alcibíades" sería en $T M$ una perfecta introducción a la exposición, no profanatoria sino explicativa, de los mitos y $\sigma u ́ \mu \beta o \lambda \alpha$ de los misterios.

A continuación (13.1) - tras 12.2, una pura diatriba de Clemente - ven-

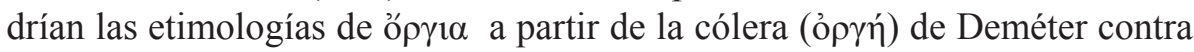
Zeus y de $\mu v \sigma \tau$ ́n etimologías son simétricas, dan unidad al conjunto, y se corresponden con los relatos que vienen después, así que pueden atribuirse sin problemas al afán clasificatorio del tratado. En cambio la etimología de $\mu v \sigma \tau$ pııv a partir de Mvoṽ , de clara intención polémica y que rompe la simetría, es introducida por Clemente a partir de Apolodoro.

Sigue una lista de fundadores de misterios en orden alfabético (II 13.3): Dárdano, Eetión, Midas, Melampo. Tan sólo Cíniras, inserto entre los dos últimos, lo rompe. Pero ya hemos visto que este personaje es con toda probabilidad una adición de Clemente a la narración de los misterios de Afrodita, y por tanto aquí también debe de ser un añadido.

Comienza entonces la exposición de los misterios particulares. El orden es

21 Mora 1994, pp. 70-73 y 156-162 sostiene que Clemente introduce muchos cambios en una fuente mitográfica reciente, p. e. las noticias rituales. Pero éstas vienen del tratado (Clemente copia $\sigma 0 ́ \mu \beta о \lambda \alpha$ que no llega a entender, cosa que no haría si no estuvieran en su fuente).

22 Riedweg 1987, p. 122: "von eine Profanierungabsicht ist es keine Rede". Sin embargo, la imagen de una acusación judicial contra los misterios lleva a enfatizar el "desvelar el secreto" en expresiones que se acercan a la profanación: 14.1, 21.1, 22.4. A Clemente le importa más la efectividad retórica que la coherencia.

EMERITA (EM) LXXV 1, enero-junio $2007 \quad$ pp. 19-50 ISSN 0013-6662 
siempre el mismo, el relato mítico que precede a los objetos rituales, y la continuación del mito hasta enlazar con los misterios siguientes. Los primeros misterios, siguiendo el orden alfabético, son los de Afrodita. Descartada la mención de Cíniras, $T M$ cuenta que nacida del mar y de los genitales de

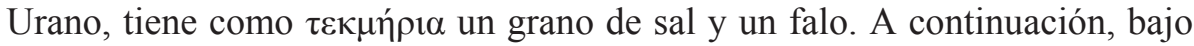
el epígrafe de "misterios de Deo", con la narración de los incestos de Zeus con su madre Rea-Deméter y su hija Core, TM agrupa los de Cibele y los de Sabazio: si bien en los primeros la narración mítica no justifica el $\sigma 0 ́ \mu \beta 0 \lambda o v$ (15.3), en los segundos sí (16.2) ${ }^{23}$.

Esta sección acaba con los versos de un poeta "idolátrico" referidos al hijo tauromorfo de Feréfata. Los versos son oscuros y no son hexámetros (salvo corrupción textual irremediable) pero puesto que Clemente reconoce

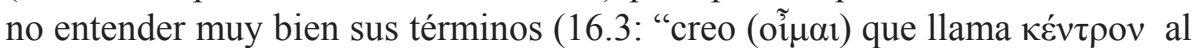
váp$\theta \eta \xi ")$, es claro que debían estar ya en su fuente refiriéndose al nacimiento de Dioniso. Estos versos son además la conexión lógica del mito anterior con los misterios de Dioniso, cuya exposición empieza en 17.2, tras anticipar en 17.1 el mito de Feréfata ${ }^{24}$. La sección sobre Dioniso tiene la estructura habitual: narración que justifica los $\sigma 0 ́ \mu \beta o \lambda \alpha$ (los juguetes), seguida del final de la narración (18.2).

Lo siguientes misterios (19.1-4) son los de los Coribantes: el asesinato de un tercer hermano justifica el tabú del apio. La identificación con los Cabiros permite la asociación con el crimen de Dioniso relatado justo antes, pues los dos hermanos fratricidas llevaron en una cesta mística los genitales del dios y fundaron los misterios cabíricos: hay una identificación clara del tercer hermano muerto con Dioniso ${ }^{25}$. Veremos en el punto siguiente que esta parte

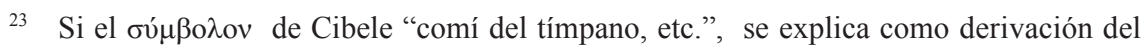

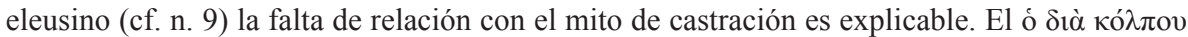
$\theta \varepsilon o ́ \varsigma$ se puede poner fácilmente en relación directa, como ya hace el texto mismo, con el incesto de Zeus convertido en serpiente.

24 La breve anticipación del relato de los misterios eleusinios antes de describir los de Dioniso debe provenir del mismo Clemente, que se habría dejado llevar por la continuidad del personaje de Feréfata antes de hablar de su hijo Dioniso. Se ve en el $\gamma \alpha \dot{\rho} \rho$ de 17.2 (que Marcovich en su edición sustituye por $\delta \varepsilon$ )́, que pierde su sentido tras la anticipación de 17.1: es un rastro de la conexión que en $T M$ y $T g$ tenía el relato de Dioniso con el hijo tauromorfo de Core.

25 Las excavaciones en el santuario de los Cabiros confirman la relación del Niño con Dioniso, por lo que su asociación con el mito de los Titanes no era difícil (Guthrie 1951, pp. 123-126), al igual que con Coribantes y Curetes. Cf. Linforth 1941, pp. 203-205 sobre Orfeo 
parece ser una novedad de $T M$ respecto a $T g$, al contrario que los demás episodios basados en el poema órfico.

Y por último, TM describía los misterios de Feréfata, cuyo comienzo Clemente había anticipado en 17.1 aludiendo al rapto de la joven y a los cerdos del porquero Eubuleo, cuya caída por una sima se conmemora en el ritual de las Tesmoforias. En 20.1 se retoma la narración con la búsqueda de Core por su madre y el encuentro con los habitantes del Ática. La versión del episodio, atribuida explícitamente a Orfeo, es distinta de la del Himno Homérico a Deméter: Baubo asume el papel de Yambe, ofrece a Deméter el ciceón y la hace

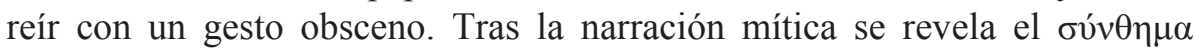
eleusino. Como se ha visto, es probable que el tratado contuviera al final de este apartado la mención de los misterios de Ge Themis.

Aquí conviene aludir al único otro testimonio que parece derivar de $T M$. Un escolio a Luciano, cuya familiaridad con la fuente de Clemente se reconoció desde su publicación por utilizar el nombre Arretoforia en vez de Arreforia, (como en Protr. II 17.1) explica el ritual de las Tesmoforias ${ }^{26}$. La dis-

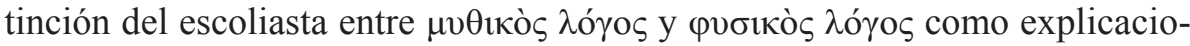
nes complementarias de los rituales no tiene correspondencia alguna en el texto de Clemente, así que debemos concluir que proviene del escoliasta mismo o de su fuente, que mezcla la información mitográfica y ritual de $T M$ con explicaciones físicas del mito. Si ese tipo de distinción hubiera estado en $T M$, probablemente habría quedado algún resto en el texto clementino.

\subsection{Las fuentes del tratado: un poema órfico}

Por el orden en que se describen los misterios, parece claro que $T M$ enmarca un relato mitológico en un esquema enciclopédico y organizado en secciones. Tras las etimologías y los fundadores de los misterios, la descripción tiene un claro tono narrativo. La continuidad genealógica entre los mis-

como fundador de cultos en Frigia y Samotracia.

26 Schol. Luc. Dial. Meretr. 2.1 (275, 23 Rabe) = OF 390 II. Cf. Robertson 1996, pp. 365-372 sobre el ritual descrito. Rohde 1870 descubrió y editó este escolio, junto con otro al Dial. Meretr 7.4. (279, 24 Rabe), que habla del ritual de las Haloa en un tono muy similar y

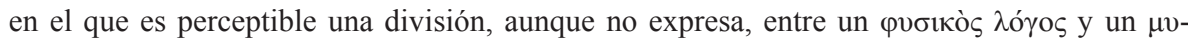

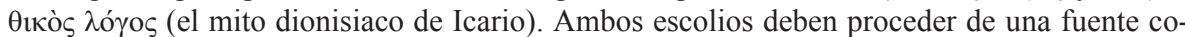
mún que a su vez debió usar a TM. El escolio 52.9 (212, 20 Rabe) para explicar los misterios de Sabazio cuenta brevemente la violación de Perséfone por Zeus transformado en serpiente (OF 280, 283), por lo que también debe de provenir de la misma fuente. 
terios de Deó y Dioniso es tan clara, y corresponde tan exactamente a los relatos teogónicos órficos - incestos sucesivos de Zeus con Deméter y Core y nacimiento de Dioniso de esta última - que cabe escasa duda de que al menos en esta parte el tratado sigue una teogonía órfica $(T g)$, de la que se conservan los versos de Orfeo citados en 17.2 sobre los juguetes y los que se perciben detrás del relato en prosa: salvo que se suponga una corrupción in-

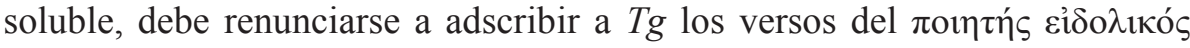
citados en 16.3, pues a Orfeo se le atribuyen hexámetros. Tal vez estos versos sean un tipo de $\sigma v ́ v \theta \eta \mu \alpha$ que sólo los iniciados comprenderían. Por la misma razón métrica, en principio los $\sigma u ́ \mu \beta o \lambda \alpha$ y $\sigma v v \theta \eta ́ n \alpha \tau \alpha$ no formarían parte en principio de $T g$, aunque el poema narrara los mitos que los justificaban. Serían añadidos por el autor de $T M$ a partir de otra fuente (tal vez ípoì $\lambda$ óyor como el $P$. Gurob) o por conocimiento general. Pero la conexión ritual de los poemas órficos impide asegurar que siempre se editaran sin interferencia de frases rituales extra metrum. En las laminillas de oro o en el mismo $P$. Gurob los hexámetros intercalan frases rituales extra metrum, y es probable que $T g$ también lo hiciera, si tenía algún uso ritual.

Antes de los incestos de Zeus, no es problemático adscribir el nacimiento

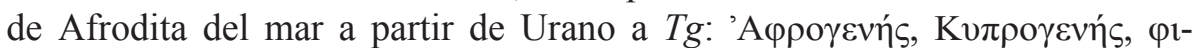

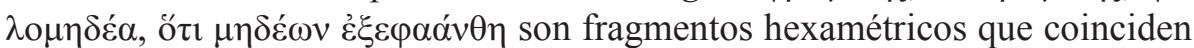
con Hesíodo (Theog. 195-200) pero que encajan también perfectamente con la poesía de Orfeo, que canta este mismo episodio en las Rapsodias, que como es sabido reúne el material órfico anterior ${ }^{27}$. El interés puramente ritual del autor de TM y su organización alfabética provoca la omisión de los episodios teogónicos iniciales y los que median entre el nacimiento de Afrodita y los incestos de Zeus, episodios sin conexión inmediata con $\tau \varepsilon \lambda \varepsilon \tau \alpha i ́$ pero que tal vez sí estuvieran en $T g$. Si $T M$ los hubiera recogido, sería raro que Clemente hubiera dejado de explotar para sus burlas, como hacen otros apologistas, el que Crono devorara a sus hijos o el parricidio de Zeus.

Siguiendo adelante, cabe preguntarse si los incestos de Zeus estaban plenamente desarrollados en el poema o aludidos de pasada, como ocurre por ejemplo en la Teogonía de Derveni. El estilo rápido y alusivo de Clemente en

27 OF 189. Una segunda Afrodita nace en $O F$ 260, a partir de Zeus, pero también de la espuma. Cf. ahora Betegh 2004 sobre ambas a propósito de su presencia en el P. Derveni. Si es cierta esta hipótesis, la presencia del nacimiento de Afrodita a partir de los genitales de Urano en la tradición poética órfica es al menos de principios de época helenística, lo cual precisa un poco más la fecha helenística que le da West 1983, p. 216.

EMERITA (EM) LXXV 1, enero-junio $2007 \quad$ pp. 19-50 ISSN 0013-6662 
15.1 da la impresión de lo segundo: "las uniones amorosas de Zeus y la cólera de Deó y las súplicas de Zeus y la bebida de hiel y extracciones del corazón y

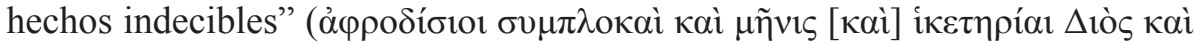

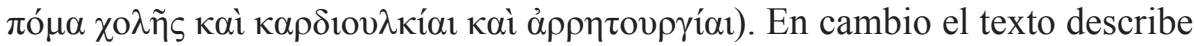
un oscuro episodio de castración de un cabrito en lugar de Zeus, que recuerda a un ritual egipcio descrito por Heródoto y a su vez puede ser la etiología de los ritos de Cibele en los que los galloi se castraban ${ }^{28}$. Así que el interés ritual no es sólo de $T M$, sino parece ser también la orientación de $T g$, que narraba este episodio. Lo mismo puede decirse de la insistencia en la segunda unión con Core en forma de serpiente y la forma de toro de Dioniso al nacer ${ }^{29}$, pues tanto la serpiente como el toro tienen claras connotaciones rituales, la primera como símbolo ctónico y el segundo como víctima sacrificial.

El interés ritual del poema se refleja en especial en el episodio siguiente de Dioniso, y no sólo porque narra la danza de los Curetes armados y los juguetes de Dioniso (elementos rituales ambos, como demuestra su aparición en el $P$. Gurob). Hemos visto además que el resumen en prosa conserva la huella de un verso similar, probablemente idéntico, a Il. XVI 677 (

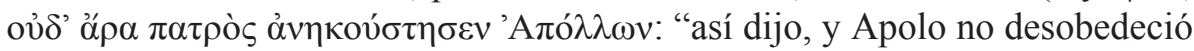
a su padre"). Puede suponerse que la orden de Zeus también era paralela a $I l$.

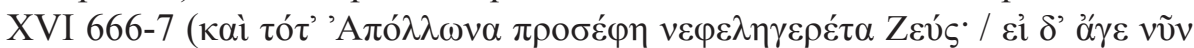

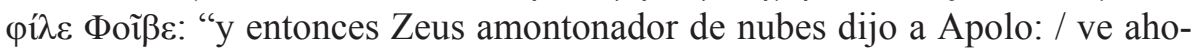
ra, querido Febo"). Ambos versos enmarcan la escena homérica que etiologiza el entierro de Sarpedón en Licia y la instauración de su culto alli ${ }^{30}$. El paralelo con el culto de Dioniso en torno a su tumba de Delfos, etiologizado en este mito, no deja lugar a dudas: el pasaje órfico sobre el entierro de Dioniso tenía con toda probabilidad la misma estructura formal que el de Homero sobre Sarpedón ${ }^{31}$.

28 Hdt 2.42. Aparte de Clemente (y a partir de él Arnobio, Adv. Nat. 5.20), sólo Pausanias (2.3.4) hace una furtiva mención de este mito. Cf. Burkert 1983, p. 283.

29 Protr.16.1-3. Es la tradición que recogen Fírmico Materno (De err. 6) y Nono (Dion.6.205) al presentar al Dioniso órfico tauromorfo, aunque en el momento de su muerte.

30 Los mismos versos se repiten en otra orden a Apolo en Il. XV 220-236. Probablemente el poeta órfico los copia de Homero, aunque no cabe descartar que si estos versos son antiguos, el paralelo venga del caudal formular común a toda la poesía hexamétrica. Cf. Herrero (en prensa).

31 La conexión délfica de este episodio ha sido reconocida por West 1983, p. 151 y Robertson 2003. El paralelo con el pasaje homérico es la posible causa de que Zenódoto atetice todo el pasaje sobre el entierro de Sarpedón, según transmiten los escolios, por considerarlo

EMERITA (EM) LXXV 1, enero-junio $2007 \quad$ pp. 19-50 ISSN 0013-6662 
Este episodio tiene aún muchos otros puntos de interés: por lo que deja traslucir Clemente, según hemos visto, el poema también enfatizaba los detalles culinarios del sacrificio de Dioniso tras su desmembramiento ${ }^{32}$ : el $\pi \rho o ́-$ $\tau \varepsilon \rho \circ$... हैं $\pi \varepsilon \imath \tau \alpha$ del texto deja claro que el orden cocer-asar es buscado y puesto de relieve, probablemente con una referencia deliberada (Il.426-428, tal vez Il. IV 49) a las escenas homéricas que describían el sacrificio tradicional. Posiblemente la inversión del orden habitual del sacrificio pretendía reflejar la perversión del ritual que supone el crimen de los Titanes ${ }^{33}$.

Cabe preguntarse también si el episodio acababa con el entierro de Dioniso en Delfos. Que Atenea guarde el corazón de Dioniso sólo tiene pleno sentido si éste va a resucitar a partir de él, como hace en las Rapsodias (OF 318331). Sería lógico que Clemente hubiera silenciado esta parte, que no conviene a su polémica porque no puede burlarse, obviamente, de la resurrección de un dios. Por otra parte, es posible que ni siquiera el autor de $T M$ la recogiera, ya que la eventual resurrección de Dioniso no afecta a lo que a él le interesa, el ritual. E incluso, como no es estrictamente necesaria para la etiología del culto, que parece ser el interés principal de $T g$, puede que bastara con dejarla

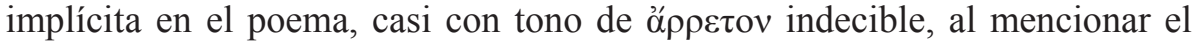
corazón salvado por Atenea. La etimología de Palas Atenea a partir del latir $(\pi \alpha ́ \lambda \lambda \varepsilon v v)$ del corazón sí es probable que apareciera en el poema mismo, puesto que la encontramos también en las Rapsodias (OF 316) como ocurría con la de Afrodita. Tampoco Clemente hace ninguna alusión a que de las cenizas de los Titanes surgieran los hombres, y no hay indicio alguno de que $T g$ aludiera a ello.

impropio de Homero: el ser parecido a un poema órfico lo convierte a sus ojos en típica interpolación de los neoteroi, los poetas posteriores a Homero, entre los que para los alejandrinos se contaban los poetas órficos. Cf. Herrero (en prensa).

32 Según Robertson 2003 esta versión sería una composición artificial de dos temas míticos anteriores separados, el del despedazamiento y el del sacrificio. No me parece probable porque ambos temas son perfectamente compatibles desde antiguo: de hecho, la primera noticia de la muerte de Dioniso, de Euforión (fr. 13 De Cuenca = 14 Van Groningen = OF 36), ya vincula los dos temas. Por eso Robertson se ve forzado a enmendar el texto de Euforión para sostener su artificial distinción.

33 Esta perversión enfatizaría la maldad del crimen de los Titanes, un episodio que podía

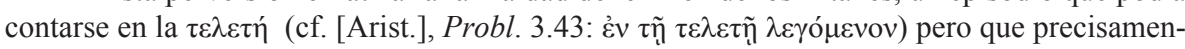
te por ello es improbable que se reactualizara, es decir, que un sacrificio perverso se convirtiera en un $\delta \rho \omega ́ \mu \varepsilon v o v$ de los ritos órficos, como pretende Detienne 1977, que señaló el orden extraño del sacrificio titánico. Parker 1995, p. 509 n. 93, señala que el orden habitual es cocer unas partes y asar las entrañas, lo cual rompe la simetría alegada por Detienne y con ella su interpretación de sistema alternativo a la polis. 
Siguiendo adelante, parece más dudoso que el episodio de los Coribantes perteneciese a $T g$. No se perciben restos poéticos en la narración en prosa, y el vínculo con Dioniso no es genealógico, sino que, después de empezar una nueva historia con los dos hermanos fratricidas, pretende hacer derivar el rito cabírico - y de paso el de Atis (Protr. II 19.4) - del mito de los Titanes por vía del aỉooĩov de Dioniso. Toda esta parte habría sido, en mi opinión, obra del autor de $T M$, pero no pertenece a $T g$. Apoya esta idea que ninguno de los paralelos con el Papiro de Gurob aparezca en esta sección.

Finalmente tenemos el rapto de Feréfata y el episodio de Deméter y Baubo. La ligazón con los sucesos anteriores es clara, a través de Feréfata, madre de Dioniso (por eso Clemente adelanta un resumen del episodio tras el parto de Feréfata en 17.1). Además, tenemos de nuevo versos atribuidos explícitamente a Orfeo $(21.1=O F 395)$. Cabe, claro es, la posibilidad de que el autor de $T M$ haya unido dos poemas distintos de Orfeo, uno que culminara en Dioniso $(T g)$ y otro que contara el episodio de Deméter y Baubo. Pero postular dos poemas órficos distintos parece más fruto del prejuicio de que dos temas diferentes han de cantarse en dos poemas separados: prejuicio injustificado, pues también en las Rapsodias acabó incluyéndose el mito del rapto de Core (OF 289-295). Cuando además aparecen unidos en $T M$, y hay una fácil conexión genealógica y temática, lo más probable es que hubiera un solo poema órfico $(T g)$ en que $T M$ se inspirase, y que cubriese desde los orígenes teogónicos hasta la fundación de los misterios de Eleusis.

\section{Origen, datación y autoría de las fuentes de Protr. II 12-22}

Una vez determinado en lo posible el contenido de $T M$ y de $T g$, tratemos de aproximarnos en lo posible a su fecha y lugar de composición. En este caso, el orden lógico es el inverso al anterior, primero el estrato más antiguo, es decir, el poema, y después el más tardío, el tratado.

\subsection{El poema órfico}

¿Cómo se enmarca $T g$ en el panorama de las teogonías órficas? Es difícil establecerlo porque las posibles omisiones de $T M$ primero y de Clemente después impiden determinar su contenido con exactitud suficiente, en especial en lo que atañe a las primeras generaciones de dioses. Pero lo poco que conocemos de $T g$ no permite identificarla con ninguna de las teogonías órfi- 
cas conocidas ${ }^{34}$ : no hay rastros de los embarazos creativos de Zeus o de Protógono como en las teogonías de Derveni, Jerónimo o Helánico o las Rapsodias, ni figuras como Noche, Océano o Tetis que protagonizan la de Eudemo. Con ninguna de ellas concuerda, además, la datación que estableceré como más probable en torno al III a. C. Pero aparte de estas teogonías órficas "bautizadas" había otras circulando desde época clásica cuyos contenidos se solapaban con las de Eudemo o Derveni y que pudieron revertir en teogonías posteriores como la de Jerónimo y Helanico o las Rapsodias. Situar a $T g$ en este grupo permite explicar sin problema los solapamientos de episodios míticos. Más útil es examinar qué rasgos comparte con otras teogonías y qué elementos la diferencian.

Es común a ésta y a otras teogonías una estructura narrativa, que va desde los dioses primigenios como Afrodita (puede suponerse que antes se hablaba de Urano y sus antecesores, si los tenía), hasta los episodios más cercanos al hombre, como la etiología mítica de las Tesmoforias. El gusto por la etimología está presente desde Hesíodo: los nombres de Afrodita, Brimó y Palas son objeto de etimologías más o menos agudas, y continuarán siéndolo en las tardías Rapsodias (OF 189, 260, 316). También los temas de $T g$ son compartidos con otras teogonías: el nacimiento de Afrodita, los incestos de Zeus, el crimen de Dioniso, el rapto de Perséfone, están atestiguados en muchas otras fuentes. Tan sólo el episodio de Zeus castrando a un cabrito en sustitución de sí mismo para aplacar la cólera de Deméter y el gesto de Baubo se encuentran sin paralelo en otros relatos teogónicos: este aislamiento puede deberse al azar, pero parece proceder sobre todo de la estrecha vinculación de $T g$ al ritual. Su verdadera originalidad e interés no radica en su estilo ni en sus temas, sino en su marcada orientación ritual. La ausencia total de especulación cosmogónica y teológica, tan presente en el resto de teogonías órficas - desde la de Derveni hasta las Rapsodias, pasando por la de Jerónimo y Helanico - y la concentración absoluta en el mito que da origen al ritual, no parece que sea sólo producto de la selección de $T M$ y Clemente, sino que es probable que ya estuviera presente en $T g$. Esta tendencia es patente en diversos detalles: hacer de la historia de Baubo, una clara etiología mítica de un rito, el culmen de la narración; enfatizar en los incestos de Zeus los gestos de origen ritual (castración del cabrito, transformación en serpiente); destacar no que nazca Dioniso, sino que nace tauromorfo; y sobre todo, todos los sucesos

34 Sobre estas teogonías, cf. West 1983 (que encuadra arbitrariamente el material clementino en la teogonía de Eudemo, p. 267) y Bernabé 2004 (vol I).

EMERITA (EM) LXXV 1, enero-junio $2007 \quad$ pp. 19-50 ISSN 0013-6662 
orientados a justificar un culto que encontramos en la narración del mito de los Titanes: la danza curética, los juguetes, el orden del sacrificio invertido, el caldero sobre el trípode, el entierro de Dioniso en el Parnaso, todos ellos son elementos que encontramos utilizados en múltiples cultos y que tienen en este caso una clara orientación délfica ${ }^{35}$.

¿Dónde cabría en $T g$ algo como el Himno a Zeus que un lugar tan central ocupa en la teogonía de Derveni (OF 14) o en las Rapsodias (OF 243)? La falta de altos vuelos especulativos y la concentración en el rito no es fruto solamente de la selección de TM: si $T g$ era capaz de servir de base a un tratado enciclopédico sobre los ritos, es porque el poema mismo ya lo era en buena parte. Hay así una gran continuidad entre el poema y su interpretación ${ }^{36}$. El afán de enlazar ritos diversos mediante la conexión genealógica entre dioses no es sólo del tratadista de $T M$. También el poeta órfico de $T g$ ha enlazado los ritos de la Madre y Sabazio en una narración continua. Se ve sobre todo en la conciliación dentro de una misma narración mitológica de dos versiones de la historia de Core -su violación y embarazo por Zeus, y su rapto por Hades- que son muy difícilmente conciliables ${ }^{37}$. El autor de $T g$, como el de las Rapsodias, une diversas versiones órficas, procedentes de diversos cultos, en una sola.

Cabe preguntarse, entonces: del mismo modo que las Rapsodias unificaban la tradición órfica bajo la égida de la ideología estoica, ¿al servicio de qué interés o de quién se compuso el poema que tratamos? Aunque se otorga gran espacio a los misterios de Dioniso, son los misterios de Deméter los máximos beneficiarios del relato teogónico que culmina en ellos el recorrido mítico y ritual por diversos cultos. Llamada por su epiclesis poética Deó, Deméter subsume los misterios de la Madre, y adquiere prioridad cronológica sobre los de Sabazio y Dioniso. Pero además al ser los últimos, con un relato en el que ya aparecen los hombres, no los dioses primigenios ni sus ancestros los Titanes, parece ofrecer en los misterios de Deméter (Tesmoforias y Eleusis) la culminación que supera y engloba los anteriores. El mismo hecho de que Clemente acabe la sección con un ataque a los ritos eleusinios (II 22.6-7) indica que veía

35 West 1983, p. 160ss y Robertson 2003.

36 La misma continuidad entre el poema y su interpretación se encuentra en el $P$. Derve$n i$ en que el comentarista desarrolla en prosa ideas cosmológicas implícitas en el poema (Betegh 2004). En este caso el nivel es la especulación cosmológica y teológica, no ritual, pero la correspondencia es similar.

37 West 1983, p. 95. 
en ellos el representante de todos los misterios griegos, tal vez no sólo por cultura general, sino inducido por la orientación de su misma fuente.

Este interés proeleusinio puede servir de guía para tratar de establecer el origen de la teogonía en cuestión. Una opción evidente es pensar que la propaganda proeleusinia apunta a Atenas. Pero también puede apuntar al distrito alejandrino de Eleusis, que albergaba unos festivales inspirados en los de su homónima ateniense (además de los que se celebraban en el Tesmoforion alejandrino) ${ }^{38}$. Es imposible decidirse resueltamente por ninguna de las dos, pues los poemas órficos de ámbito eleusinio eran muchos y son muy mal conocidos ${ }^{39}$, pero hay una serie de indicios que parecen apoyar más la opción alejandrina. Aunque puede caerse en la tentación de explicar obscura per obscuriora, merece la pena exponer los argumentos a favor de un origen alejandrino, que debe considerarse, si no como certeza, sí como posibilidad.

El principal indicio es la conexión que el episodio de Baubo parece tener con Egipto, que diversos estudiosos han propuesto encuadrar en el festival del distrito alejandrino de Eleusis ${ }^{40}$. Aparece mencionada en dos papiros (aparecidos, claro es, en Egipto) en contexto eleusinio: P. Berol. 44 (II a. C.) y P. Cornell 51 (I d. C.). En el primero es la reina o la nodriza; en el segun-

38 Los testimonios sobre los festivales de la Eleusis alejandrina son contradictorios, entre los que apoyan su existencia (P. Ant. 18, Porph., Peri agalm. 10.71 apud Euseb., PE III 11.45) y los que atestiguan que los misterios de Eleusis no podían celebrarse fuera de su sede ática (Epict., Ench. III 21.11-14, P.Oxy.1612). Claudio fracasó en su empeño de trasladar el culto a Roma (Suet. Claud.25), pero si lo intentó, no debía ser tema en que no cupiera discusión. Cf. Fraser 1972, II, p. 339ss y Clinton 1974, p. 8. Tolomeo trajo al Eumólpida Timoteo como experto en Eleusis para ayudar al culto de Serapis (Tac., Hist. IV 83, Plut., De Is. 28, 362a). Probablemente es el mismo Timoteo el "destacado teólogo" que Arnobio (Adv. Nat. 5.5-7) cita como autoridad para el mito de Atis y Cibele. Se ha sospechado (Nilsson $1961 \mathrm{II}^{2}$ pp. 94-95; Mylonas 1961, p. 300s.) que tan polifacético teólogo-sacerdote itinerante pudo transmitir elementos eleusinios a Alejandría. Me parece aceptable el juicio de Nilsson 1957, p. 66: "The Eleusinian mysteries were not transferred to Alexandria, but the cult of Demeter in this city was influenced by them" (en tono similar, Burkert 1987, pp. 37-38). Ello explicaría la confusión del escoliasta que cree erróneamente que el Himno a Deméter de Calímaco se refiere a festivales alejandrinos fundados a imitación de los de Atenas (Schol.Call.Hy.6.1). La literatura órfica sería un buen vehículo de transmisión de esta influencia.

39 Graf 1974 y en prensa.

40 A favor de situarlo en la Eleusis alejandrina, entre otros, Nilsson 1960, p. 659; Mylonas 1961, p. 287ss.; Kerenyi 1962, pp. 107-12. En contra, Picard 1927 trata de sostener un origen antiquísimo de la figura de Baubo como personificación sexual, que se simbolizaría y sustituiría por Yambe en la propia Ática al resultar demasiado cruda. También Burkert 1983, cf. n. 44. 
do, la madre de Triptólemo. En ambos, pues, es una mujer vinculada con los habitantes de Eleusis a la llegada de Deméter, mientras que en los testimonios de Grecia es una diosa, y en Asia Menor, una ménade ${ }^{41}$. Y sobre todo, el

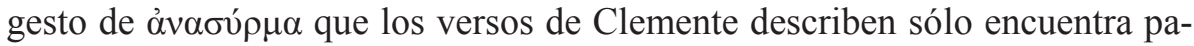
ralelo en un gesto ritual, descrito por Heródoto, de las mujeres egipcias de Bubastis ${ }^{42}$. Nada parecido encontramos en Grecia. Por fin, la iconografía de Baubo apoya también su emplazamiento alejandrino ${ }^{43}$.

Cierto es que Clemente sitúa expresamente la narración en Atenas, nada

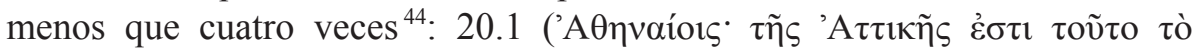

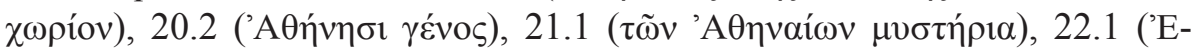
$\rho \varepsilon \chi \theta \varepsilon \varepsilon \delta \tilde{\omega} v \delta \eta ́ \mu o v)$. Pero tanta insistencia resulta sospechosa: la aclaración de que Eleusis se refiere al Ática resulta superflua si no hay posibilidad de

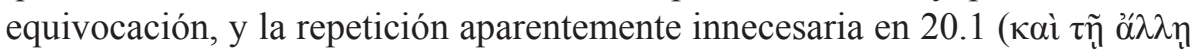

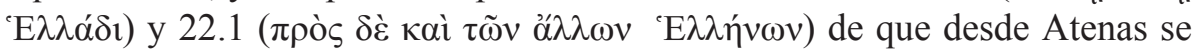
extendió al resto de los griegos hace suponer que cree que entre su audiencia el contexto ateniense podría no estar tan claro. Por supuesto que la narración mítica no puede tener lugar más que en la Eleusis ática. La afirmación de Clemente, sin embargo, de que los ritos derivados del relato son atenienses

41 En Grecia, SEG 27, 1977, 280 (IV a. C.) e $I G$ 12.5.227 (I a. C.). En Asia Menor, $I$. Magn. 215(a), 35. Cf. Henrichs 1978, p. 131, y aparato crítico al OF 391.

42 Hdt. II 59-60, D. S. I 85. Scarpi 2001, p. 468 menciona un episodio similar en la mitología egipcia que tiene como protagonista a la diosa Hathor, que hace reír a su padre mostrando sus genitales.

43 El LIMC muestra figurillas de Baubo, todas ellas provenientes de Egipto, en que aparecen identificados los genitalia femeninos, un rostro humano y un cerdo ( $\chi$ oĩpos, de lo que 'I $\alpha \kappa \chi o \varsigma$ puede ser sinónimo, cf. LSJ s. v.). El verso citado por Clemente en II 21.1 en que se menciona a Yaco probablemente juega con el doble sentido del nombre del Dioniso eleusino (como sugiere Marcovich 1986) y de pudenda muliebra, tal como lo entendió Arnobio en su traducción (Graf 1974, pp. 194-199, siguiendo una antigua idea de Diels que el LIMC no menciona). Ambas interpretaciones pueden valer simultáneamente, pues es precisamente el juego de palabras que acompaña al juego visual la clave de los versos. El único testimonio no egipcio está en el templo helenístico de Deméter y Core de Priene (Asia Menor) donde aparecen unas estatuillas con la confusión del rostro y los genitales femeninos, lo cual hace suponer la misma base antropológica, aunque no puedan identificarse con seguridad con Baubo. Cf. Olender 1985 y O’Higgins 2001.

44 Éste es el sencillo argumento de Burkert para descartar el origen alejandrino (1983, pp. 269-70): "Clement could have hardly expected his Alexandrian public to accept something Alexandrian as Eleusinian". El $\kappa \alpha \tau \grave{\alpha} \pi$ ó $\lambda \iota v$ de 17.1 no se refiere a Atenas ("en la ciudad") sino que tiene sentido distributivo, para decir que "en cada ciudad" se celebra de manera distinta el mismo episodio. Ch. Riedweg, que en 1987, p. 119 se pronunció por un sentido local, acepta ahora (según me comunicó verbalmente) el sentido distributivo.

EMERITA (EM) LXXV 1, enero-junio $2007 \quad$ pp. 19-50 ISSN 0013-6662 
puede ser una suposición errada propia o inducida por un error de su fuente $(T M)$, o incluso por el mismo poema eleusinio alejandrino $(T g)$ que querría presentar los ritos como exactamente derivados de la Eleusis ática, pues la legitimidad del culto alejandrino venía de remontarse al de Atenas, al menos

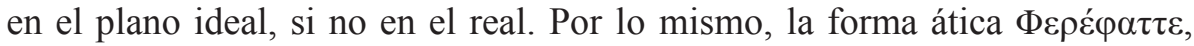
alegada como indicio de origen ateniense ${ }^{45}$, intentaría simplemente darle un color local al relato. Pero el emplazamiento del episodio mítico no tiene que coincidir con el lugar de origen del poema.

Los otros misterios incluidos en el relato teogónico no dan tan claras pistas sobre el origen de $T g$, pero son perfectamente compatibles con una raíz alejandrina: los misterios de Afrodita tenían lugar en la posesión tolemaica de Chipre; la Gran Madre frigia pasó pronto a formar parte del sistema sincrético impulsado desde el poder como "Madre de los Dioses" (título que Isis toma de ella) ${ }^{46}$. Por fin, es sabido que los misterios de Dioniso tenían un especial arraigo en el Egipto tolemaico ${ }^{47}$. Y sobre todo hay un fuerte argumento en favor de un origen egipcio: las coincidencias verbales, incluso en el mismo orden, del culto testimoniado en el P. Gurob (muy probablemente un culto egipcio) con el texto clementino, se explican mucho más fácilmente a partir de un origen alejandrino de $T g$.

Es razonable datar $T g$ en torno al s. III a. C., teniendo en cuenta que el poeta órfico, como sus predecesores y continuadores, puede utilizar libremente materiales mucho más antiguos: por un lado, el mito de Dioniso aún no ha sufrido ninguna contaminación con el de Osiris, como sucederá poco después con la aparición de versiones "osirizantes" del mito en que Rea recoge sus restos $^{48}$. Por otro, los versos sobre Baubo presentan rasgos postclásicos que corresponden a época helenística ${ }^{49}$. Y sobre todo, las coincidencias con el $P$.

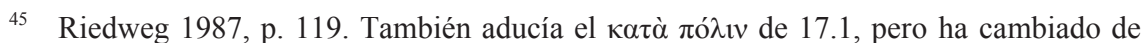
parecer (n.44).

46 Fraser 1972 I, pp. 277-279. Y Fraser 1972 II, p. 347 n. 118 para la fusión tolemaica, con la ayuda del Eumólpida Timoteo (cf. n.38) entre elementos de los cultos de Cibele ( $\tau$ $\mu$ $\pi \alpha v i \zeta \varepsilon ı v, \Gamma \alpha ́ \lambda \lambda o \imath)$ y Dioniso, que en todo caso tiene precedentes en Grecia desde época antigua (Eur. $B a$. 126-9). La rivalidad con Pérgamo pudo tal vez contribuir a pretender apropiarse de la diosa. Cf. n. 28 sobre la conexión egipcia del mito de la castración fingida de Zeus.

47 Nilsson 1957, Fraser 1972 II, p. 202ss, Burkert 1993, Casadio 1996. Aparte del $P$. Gurob, también P. Soc. Ital. 850 (OF 310 III) y P. Argent 1313 (OF 593) se refieren al mito de los Titanes.

48 Bernabé 2000 y 2002; Casadio 1996; OF 40-63.

49 Graf 1974, p. 165. Mora 1994, pp. 156-162 sostiene que la fuente mitográfica de Cle-

EMERITA (EM) LXXV 1, enero-junio $2007 \quad$ pp. 19-50 ISSN 0013-6662 
Gurob invitan a postular una composición de $T g$ en época no muy alejada de la datación del papiro ( \pm 275 a. C. $)$ ¿Es anterior o posterior al papiro? Cabría pensar que el culto del papiro se inspira en $T g$, pero más bien parece a la inversa, que el poema se compone a partir del conocimiento de cultos sincréticos como los del papiro. El elaborado ensamblaje de diversos cultos en una narración teogónica, con nombres poéticos y no cultuales como Deó y Feréfata, y con soluciones artificiales como la unión de las dos versiones del mito de Perséfone, hace pensar en una composición que quiere ofrecer un $\lambda$ ófos mítico coherente de estos cultos que fusionan diversas divinidades mistéricas. El problema, en cualquier caso, es similar al de la prioridad del huevo o la gallina, pues $T g$ puede usar material poético anterior, y además el $P$. Gurob muestra algunos hexámetros que pueden proceder de otros poemas.

Cabe recordar aquí la atractiva posibilidad de que el $P$. Gurob sea un hieros logos de los recolectados por orden del decreto de Tolomeo IV Filopátor

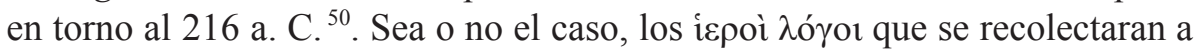
raíz del decreto debían de ser del mismo estilo. Es posible que $T g$ se compusiera con la información que esa colección había proporcionado, con la intención más o menos consciente de ordenar los cultos bajo la primacía de los de Dioniso y Deméter y de potenciar la estatalización de las $\tau \varepsilon \lambda \varepsilon \tau \alpha$ í haciéndolas culminar en Eleusis.

En cualquier caso, sea en ámbito alejandrino o ateniense donde un poeta órfico compuso $\mathrm{Tg}$, lo que no cabe duda es de que ha sabido explotar el valor panhelénico y unificador que tienen Deméter y Dioniso como divinidades y Orfeo como cantor.

mente es casi contemporánea a él por la presencia de los Curetes, por la presencia de Atenea y Apolo (un desdoblamiento "moderno") y porque la cita de Il. II 426 es propia de Clemente. Pero los Curetes aparecen ya en el $P$. Gurob, la cita iliádica es probablemente del poema órfico y la presencia conjunta de Atenea y Apolo es tan antigua como Homero. El juego con los detalles culinarios también apunta a la antigüedad del poema (cf. n.33). Mora pretende desvalorizar la fuente de Clemente para revalorizar la supuesta fuente de Arnobio (cf. n.59).

50 Wilamowitz 1931, II p. 378. Burkert 1987, pp. 70-71 relacionan el P. Gurob con $B G U$ VI 1211 (OF 44), un decreto de Tolomeo para controlar las $\tau \varepsilon \lambda \varepsilon \tau \alpha \dot{~ d e ~ D i o n i s o ~ e n ~ q u e ~}$ pide copias de los iєpoì $\lambda$ ó La abundante bibliografía sobre el decreto se encuentra comentada en Lenger 1980 y 1990. Cf. ahora también Henrichs 2003, pp. 227-231. 


\subsection{El tratado sobre los misterios}

Para datar $T M$, parece acertada la horquilla temporal deducida por Riedweg 1987, p. 122s: como terminus post quem la aparición del orden alfabético en el III a. C., y como terminus ante quem el I a. C. por la ausencia de cultos orientales como Isis o Mitra en un tratado sobre los misterios. Algunos otros detalles de $T M$ me inducen a proponer como fecha de su composición la parte alta de esta horquilla, es decir, entre el III y el II a. C., no mucho después de la teogonía en que se basa $(T g)$.

Un primer factor es la ausencia de influencia de los más importantes estudiosos de la religión en época helenística: Apolodoro (recordemos que su cita en 12.2 parece introducida por Clemente), Evémero (los párrafos evemeristas sobre Cíniras y Afrodita también son probablemente inserciones clementinas). Tampoco hay huella de las explicaciones físicas del mito, que en cambio sí recoge el mencionado escolio a Luciano que se inspira en parte en TM. Así, mientras Filodemo tiene un interés erudito en los nombres y los mitos, probablemente siguiendo a Apolodoro, el interés de TM es práctico y cultual ${ }^{51}$. Mientras las explicaciones evemeristas o físicas del mito provienen de un interés por su naturaleza y orígenes, el tratado procura simplemente enlazar los misterios con la narración teogónica, conectando el mito con el бú $\mu$ Boגov ritual. Una explicación tan poco sofisticada de los cultos y mitos induce a pensar en una época más antigua que tardía.

El tratado tampoco recoge las variaciones que el mito de Dioniso y los Titanes sufre en época helenística, asimilándolo al de Osiris de modo que Rea recoge y entierra sus miembros ${ }^{52}$, o haciéndolo resucitar en el vientre de

51 Probablemente este tipo de tratado sincrético como TM era lo que Apolodoro

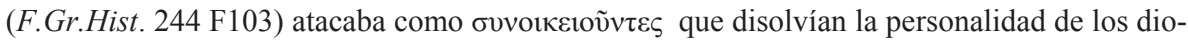
ses. En la misma línea de pensamiento está Filodemo, que habla burlonamente (OF 59 I) de los 'Орфикоí (esta palabra es reconstruida en el papiro de Herculano por Henrichs 1975, re-

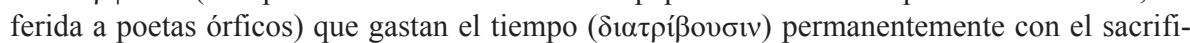
cio de Dioniso. Mientras la línea Apolodoro-Filodemo presta una atención erudita a los mitos

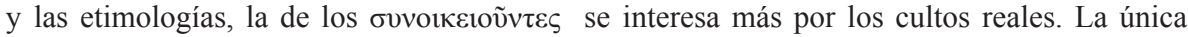
coincidencia significativa del texto de Clemente con el material mitográfico del De Pietate de Filodemo es la etimología de Palas a partir del $\pi \alpha ́ \lambda \lambda \varepsilon ı v$ del corazón de Dioniso (cf. Henrichs 1975 , p. 35 s), difícilmente compatible con la versión "osirizada" que recoge, según la cual resucita a partir de la reagrupación de sus miembros. Plutarco y Diodoro, cuyos intereses son muy amplios, toman materiales de ambas (cf. Bernabé 1996 y 2000).

52 West 1983, p. 161; Bernabé 2002, p. 89. 
Sémele ${ }^{53}$. Por supuesto que el autor puede tener resistencia a usar más de una fuente, pero la falta de mención podría apuntar a que no conoce estas versiones porque se desarrollan posteriormente. En cambio, el siglo III a. C. coincide con la época en que Calímaco y Euforión mencionan por primera vez el mito sin ambigüedad ${ }^{54}$.

$T M$ continúa, además, la orientación de $T g$ y refuerza los vínculos entre los misterios, unificándolos aún más con los nombres de Deó y Feréfata como epígrafes alfabéticos. También está dentro de la misma lógica identificar a Dioniso con Atis (19.4). Si además, como he señalado que es probable, la historia de los misterios de Samotracia como derivados de los de Dioniso proviene del autor de $T M$ y no de $T g$, entonces la continuidad ideológica es aún mayor, y parecería apuntar a una no excesiva distancia temporal entre la teogonía y el tratado. La fusión entre los Cabiros originales, los Coribantes frigios y el mito dionisiaco se sirve del orfismo como vínculo entre cultos que debían ofrecer ya múltiples similitudes. Se añade a ello el interés propagandístico por buscar el prestigio religioso en la prioridad cronológica de un culto sobre otro ${ }^{55}$.

Esta última es la consideración clave que induce a postular un probable origen alejandrino también para $T M$. No sólo es la lógica consecuencia de que su fuente principal $(\mathrm{Tg})$ sea probablemente alejandrina y que también lo sea su lector y divulgador, Clemente, la mayoría de cuyas fuentes son por cierto alejandrinas. TM encaja perfectamente en los estudios de la Biblioteca de Alejandría sobre religión, donde es lógico que el orfismo, muy vivo en Egipto en época helenística ${ }^{56}$, despertase interés. Y además parece servir también los intereses de la propaganda tolemaica, al hacer derivar los misterios de Samotracia de los dionisiacos (II 19), y los festivales de Deó en Grecia de Egipto a través de Melampo (II 13.5).

La autoría del tratado es materia de pura especulación. En el mismo Pro-

53 Bernabé 2000.

54 Ambas menciones, de contenido oscuro pero inequívocamente referidas al mito, son transmitidas por el Schol. Lycophr. $208=$ OF 36

${ }_{55}$ Es la misma lógica que la noticia inversa de que Orfeo tomó sus $\tau \varepsilon \lambda \varepsilon \tau \alpha$ í de Samotracia: D. S. IV 43.1; V 49.6; V 64.4 (cf. Linforth 1941, 27, p. 204s). Es el mismo principio que impregna el debate de la prioridad entre judeo-cristianos y paganos, y en el que Orfeo también desempeña un papel capital como transmisor de la Revelación bíblica a Grecia (p. e. [Iust.Phil.], Cohort. IX 3.4, 14.2 Su figura se convierte en un arma recurrente en estas batallas cronológicas por su fácil manipulación (Herrero 2005b, pp. 329-338).

56 Cf. n. 47.

EMERITA (EM) LXXV 1, enero-junio $2007 \quad$ pp. 19-50 ISSN 0013-6662 


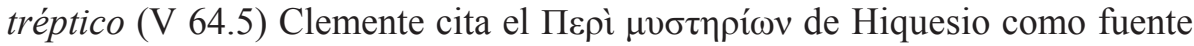
de una noticia sobre los saurómatas, pero nada más que el título de su obra le señala como posible candidato a la autoría de $T M$. De todos los autores griegos conocidos de tratados sobre misterios, hay dos nombres que merecen considerarse $^{57}$ : Arignote, mencionada por Clemente en Strom. IV 19.121, que escribió sobre las $\tau \varepsilon \lambda \varepsilon \tau \alpha$ í de Dioniso y los misterios de Deméter, y uno de cuyos dos fragmentos relaciona el grito gủoĩ con el espejo, ambos elementos presentes en el relato de Clemente. Y Apolonio de Letópolis, en

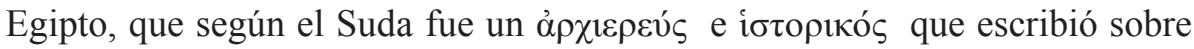
Orfeo y sus $\tau \varepsilon \lambda \varepsilon \tau \alpha$ í. Pero que tras estos nombres pueda estar el autor de $T M$ no deja de ser una mera hipótesis.

\section{Colofón}

La importancia del texto de Clemente no sólo se debe a la información que proporciona a partir de sus fuentes. Su texto agudiza la tendencia a unificar los misterios griegos que ya $T g$ y $T M$ presentaban, y la influencia enorme de su obra contribuirá a fijar la imagen de los cultos mistéricos en esta línea. Eusebio, Epifanio, Gregorio de Nazianzo, Teodoreto, escoliastas bizantinos y Miguel Pselo presentan descripciones y alusiones a los misterios griegos que no añaden prácticamente ninguna información real a la transmitida por Clemente, de modo que no es necesario postular para estos pasajes otras fuentes distintas o un conocimiento directo de los misterios. Estos textos continúan la tendencia de Clemente (y de sus fuentes) a unificar los diversos cultos en un solo ente presentándolos como una sola "superstición pagana". Sirven para medir el gran efecto de la descripción clementina (que Eusebio multiplica al copiar), pero no pueden utilizarse como fuente independiente sobre los misterios ni para reconstruir $T g$ o $T M$, porque derivan directa o indirectamente de Clemente ${ }^{58}$.

57 Recogidos en Prest 1903, p. 171ss sobre Arignote y 177ss sobre Apolonio. Burkert 1987, p. 141 n. 34 menciona el tratado sobre los misterios que parece ser fuente de Harpocración en sus comentarios al De Corona de Demóstenes: el tratado tendría como fuentes, entre otros, a Arignote y Neantes de Cízico, lo que revela que unos materiales servían de base a otros y que el conocimientos de los ritos de estos tratadistas podía ser en muchas ocasiones indirecto y libresco.

58 Eus., PE II 2.64, Epiph., Expos. fidei 10 (OF 592); Greg. Naz., Or. 5.31, Or. 39.4 (OF 384); Thdt., Affect. 1.22 (OF 525); Schol. Plat., Gorg. 497c (OF 589 II); Pselo, Quaenam sunt Graecorum opiniones de daemonibus, 3 (PG 122, c 878D 3-4 Migne). Scarpi 2001, p. 147

EMERITA (EM) LXXV 1, enero-junio $2007 \quad$ pp. 19-50 ISSN 0013-6662 
La influencia del texto del Protréptico también se deja sentir en dos apologistas latinos, Arnobio y Fírmico Materno. Parece claro que Arnobio traduce libremente a Clemente, pero es sabido que añade cierta información suplementaria a la descripción de los misterios en el libro V de su Aduersus Natio$n e{ }^{59}$. Estos detalles pueden provenir de su propio conocimiento de los cultos griegos previo a su conversión: si hay que suponer fuentes escritas, son demasiado nimios para postular un conocimiento directo de $T M$ o $T g$. Sin embargo, puesto que ambos concuerdan en los temas, hay cierta probabilidad de que las antologías de cultos paganos que servían para el uso apologético de judíos y cristianos, y de las que también Arnobio se sirve, hubieran transmitido detalles contenidos de TM que Clemente omitió, como la atribución a un poeta tarentino sobre los versos del toro y la serpiente ${ }^{60}$. También Fírmico Materno presenta grandes correspondencias temáticas, que provienen seguramente de su conocimiento de Arnobio y literatura apologética similar, aunque no cabe descartar que tuviera acceso directo también a Clemente. En cualquier caso, sus informaciones son más tardías y sujetas a una fuerte reelaboración evemerista. No contribuyen al conocimiento de $T g$ o $T M$, pero sí sirven para comprobar las diversas direcciones en que viaja su material mitográfico y religioso ${ }^{61}$.

usa el texto del escoliasta de Platón como prueba de la fusión de los cultos de Cibele y Eleusis, y Harrison $1922^{3}$, pp. 568-569 el de Pselo para probar una representación dramática de los misterios. Pero son textos que abrevian, malinterpretan o fantasean sobre lo que transmite Clemente.

59 Demuestran la dependencia de Clemente Röhricht 1893, Rapisarda 1939, Graf 1974; Marcovich 1986 específicamente sobre el texto de Baubo. El intento de Mora 1994 de resucitar la tesis de Tullius 1934 y postular una fuente distinta para Arnobio me parece infructuoso, toda vez que admite que utilizó el Protréptico en un último estadio de composición. Es más económico suponer que su fuente principal es Clemente complementada por otras indeterminables que no a la inversa. Para reforzar su idea hace un análisis erróneo de la fuente de Clemente, como antología mitográfica tardía que él habría modificado con gran libertad (cf. nn.3, 5, 21, 49). En cualquier caso, si se acepta la tesis de Mora la fuente de Arnobio derivaría, lógicamente, de TM, lo que explicaría las enormes semejanzas. Cf. a favor, la recensión de Sfameni Gasparro (BStudLat 199626 (2), pp. 636-639); en contra, las de Turcan (AC 1996 65, pp. 352-355), Champeaux (Latomus 199655 (2), pp. 427-430) y Zeller (Kernos 1996 (9), pp. 440-442).

${ }^{60}$ Clem. Alex., Protr. $16.3 \approx$ Arnob., Adv. Nat. 5.20 (OF 589). Los versos aparecen también (en griego, con el orden de palabras cambiado y sin atribución, es decir, que no proviene de Arnobio) en Firm. Mat., De err. 26.1, lo que demuestra el uso de parte del material recogido en TM en la literatura apologética aparte de Clemente.

${ }_{61}$ Coinciden con Clemente y Arnobio las referencias a Cíniras (De err. 10.1), la ser-

EMERITA (EM) LXXV 1, enero-junio $2007 \quad$ pp. 19-50 ISSN 0013-6662 
Todo este elenco de textos relacionados de un modo u otro con la descripción de los misterios en el Protréptico presenta, pues, una red de fuentes y relaciones compleja, pero susceptible de ser analizada con cierta precisión, que puede representarse esquemáticamente, a modo de conclusión, con el árbol que se encontrará al final del artículo (p. 50).

\section{REFERENCIAS BIBLIOGRÁFICAS}

Bernabé, A., 1996, «Plutarco e l'orfismo» en I. Gallo (ed.): Plutarco e la Religione, Atti del VI Convegno plutarcheo (Ravello, 29-31 maggio 1995), Nápoles, pp. 63-105.

— 2000, «Tradiciones órficas en Diodoro», en M. Alganza Roldán - J. M. Camacho Rojo - P. P. Fuentes González - M. Villena Ponsoda (eds.), EPIEIKEIA. Studia Graeca in memoriam Jesús Lens Tuero, Granada, pp. 37-53.

— 2002, «Referencias a textos órficos en Diodoro» en L. Torraca (ed.): Scriti in onore di Italo Gallo, Nápoles, pp. 67-96.

— 2004-2005, Poetae Epici Graeci II: Orphicorum et Orphicis similium testimonia et fragmenta II.1 y II.2, Múnich-Leipzig; citado como $O F$.

Betegh, G., 2004, The Derveni Papyrus: Cosmology, Theology, and Interpretation, Cambridge.

piente de Sabazio (10.2), los misterios de los Coribantes (11), los incestos de Zeus con su madre e hija (12.4), el бó $\mu \beta$ o dre del dragón (26.1). Son referencias más breves y modernizadas (p. e. el бó $\mu \beta o \lambda o v$ de 18.1) que parecen pasadas por el tamiz de las antologías apologéticas. Cf. Turcan 1982, pp. 50-52, con la bibliografía, y sus comentarios a los pasajes indicados: sin descartar que Fírmico pueda conocer directamente a Clemente (como da por seguro Rapisarda 1939, p. 36), indica que no hay pruebas incontestables y que es más probable que lo conociera a través de Arnobio. El mito de los Titanes se cuenta en versión evemerista (De err. 6, cf. Winiarczyck 1991, p. 55 y 2002, pp. 168-172), que parece aludirse en la obra judeo-alejandrina Sabiduría de Salomón 14.15-16 (West 1983, p. 172 n. 10): la conexión alejandrina y las coincidencias con el relato de Clemente (se mencionan los juguetes y el espejo, Palas conserva el corazón, Dioniso es cocinado "de varias maneras") hacen posible que el poema transformado por la fuente evemerista de Fírmico en este punto sea $T g$.

$$
\text { EMERITA (EM) LXXV 1, enero-junio } 2007 \quad \text { pp. 19-50 ISSN 0013-6662 }
$$


Burkert, W., 1983, Homo Necans: The Anthropology of Greek Sacrificial Ritual and Myth, Berkeley - Los Angeles - Londres, (trad. ingl. del orig. alemán de 1972).

- 1987, Ancient Mystery Cults, Cambridge Mass - London.1993, «Bacchic Teletai in The Hellenistic Age» en J. Carpenter- C. Faraone (eds.), Masks of Dionysus, Ithaca-Londres, pp. 259-275.

Casadio, G., 1997, Vie gnostiche all'immortalità, Brescia, 19-66 (=Antropologia gnostica e antropologia orfica nella notizia di Ippolito sui sethiani, Sangue e antropologia nella teologia, Roma, 1989, pp. 1295-1350).

- 1996, «Osiride in Grecia e Dioniso in Egitto», en I. Gallo (ed.): Plutarco e la Religione, Atti del VI Conegno plutarcheo (Ravello, 29-31 maggio 1995), Nápoles, pp. 201-227

Clinton, K., 1974, The Sacred Officials of the Eleusinian Mysteries, Filadelfia.

Detienne, M., 1977, Dionysos mis a mort, París.

Eizenhofer, L., 1960, «Die Siegelbildvorschläge des Clemens von Alexandrien», JAC 3, pp. 51-69.

Fraser, P. M., 1972, Ptolemaic Alexandria I-III, Oxford.

Graf, F., 1974, Eleusis und die orphische Dichtung Athens in vorhellenistischer Zeit, Berlin -New York.

- (en prensa), «Orfismo y Eleusis» en A. Bernabé - F. Casadesús (eds.), Orfeo y la tradición órfica: un reencuentro, Madrid.

Guthrie, W. K. C. 1952, Orpheus and Greek Religion: A Study of the Orphic Movement, London ( $\left.2^{\circ} \mathrm{ed}.\right)$.

Hardie, A., 2004, «Muses and Mysteries», en P. Murray - P. Wilson, Music and the Muses, Oxford.

Harrison, J., $1922^{3}$, Prolegomena to the Study of Greek Religion, Cambridge.

Henrichs, A., 1975, «Philodems De Pietate als mythographische Quelle», Cronache Ercolanesi 5, pp. 5-38.

— 1978, «Greek Maenadism from Olympias to Messalina», HSCP 82,149-152.

— 2003, «Hieroi Logoi and Hierai Bibloi: The (Un)written Margins of the Sacred in Ancient Greece», HSCP 101, pp. 207-266.

Herrero, M., 2005, «La conversión como metáfora espacial: una propuesta de aproximación cognitiva al cambio cultural de la Antigüedad Tardía», Ilu. Revista de Ciencias de las Religiones 10, 2005, pp.63-84.

- 2007, Tradición órfica y cristianismo antiguo, Madrid.

- (en prensa), «Tradición órfica y tradición homérica» en A. Bernabé - F. Casadesús (eds.), Orfeo y la tradición órfica: un reencuentro, Madrid.

Hoek, A. van der, 1996, «Techniques of Quotation in Clement of Alexandria», Vig. Chr. 50, 223-243.

- 2005, «Apologetic and Protreptic Discourse in Clement of Alexandria», en L'apologétique chrétienne gréco-latine à l'époque prénicenienne, Entretiens Hardt 51, Vandoeuvres-Ginebra, 69-102.

Hordern, J., 2000, «Notes on the Orphic Papyrus from Gurôb (P. Gurôb 1; Pack² 2464)», ZPE 129, 131140 .

Kerenyi, K., 1962, Die Mysterien von Eleusis, Zúrich.

Lenger, M.T., $1980^{2}$, Corpus des Ordonnances des Ptolémées, Bruselas.

— 1990, Corpus des Ordonnances des Ptolémées. Bilan des additions et corrections. Compléments à la bibliographie, Bruselas.

Linforth, I. M., 1941, The Arts of Orpheus, Berkeley- Los Angeles.

Meeren, S. van der, 2002, «Le Protréptique en philosophie: essaie de definition d'un genre», Rev. Ét. Gr. 115, pp. 591-621.

Marcovich, M., 1986, «Demeter, Baubo, Iacchus and a Redactor», Vig.Christ. 40, pp. 294-301.

EMERITA (EM) LXXV 1, enero-junio $2007 \quad$ pp. 19-50 ISSN 0013-6662 
Mora, F., 1994, Arnobio e i culti de mistero, Roma.

Mylonas, G. E., 1961, Eleusis and the Eleusinian Mysteries, Princeton.

Nilsson, M. P., 1957, The Dionysiac Mysteries of Hellenistic Times, Lund.

— 1960-1961², Geschichte der Griechischen Religion, 2 vols., Múnich.

O’Higgins, D. M., 2001, «Women's Cultic Joking and Mockery: Some Perspectives», en A. Lardinois-L. Mc Clure, Making Silence Speak: Women's Voices in Greek Literature and Society, Princeton, pp. 137-160.

Olender, M., 1985, «Aspects de Baubo», RHR 102, pp. 3-55.

Picard, C., 1927, «L'épisode de Baubo dans les mystères d'Eleusis», RHR 95, pp. 220-255.

Prest, A., 1903, Die Fragmente der griechischen Kultschriftsteller, Berlín.

Rapisarda E., 1939, Clemente Fonte di Arnobio, Turín.

Riedweg, C., 1987, Mysterienterminologie bei Plato, Philo und Klemens von Alexandrien, Berlín-Nueva York.

Robertson, N., 1996, «New Light on Demeter's Mysteries: The Festival Proerosia», GRBS 37, pp. 319-379.

— 2003, «Orphic Mysteries and Dionysiac Ritual», en M. B. Cosmopoulos (ed.): The Greek Mysteries, Londres, pp. 218-240.

Rohde, E., 1870, «Unedierte Lucianscholien, die attischen Thesmophorien und Haloen betreffend», Rhein. Mus. 25, p. 548ss. (= Kleine Schriften II, pp. 355-369).

Röhricht A., 1893, De Clemente Alexandrino Arnobii in irridendo Gentilium Cultu Deorum Auctore, Hamburg. Scarpi, P., 2001, Le religioni dei misteri, Florencia.

Sourvinou-Inwood, C., 2003, «Festival and Mysteries. Aspects of the Eleusinian cult» en M. B. Cosmopoulos (ed.): The Greek Mysteries, Londres, pp. 25-49.

Turner, E. G.,1983, «The Ptolemaic Royal Edict BGU VI 1211 is to be dated before 215-14 B.C.» Festschrift zum 100-jährigen Bestehen der papyrussammlung der Österreichischen Nationalbibliothek Papyrus Erzherzog Rainer (P.Rainer Cent.) Viena, pp. 148-152.

West, M. L., 1983, The Orphic Poems, Oxford.

Wilamowitz-Möllendorff, U. von, 1931-1932, Der Glaube der Hellenen, Berlín (2 vols).

Winiarczyk, M., 1991, Evhemeri Messenii Reliquiae, Stuttgart-Leipzig.

—2002, Euhemeros von Messene: Leben, Werk und Nachwirkung. Múnich- Leipzig. 


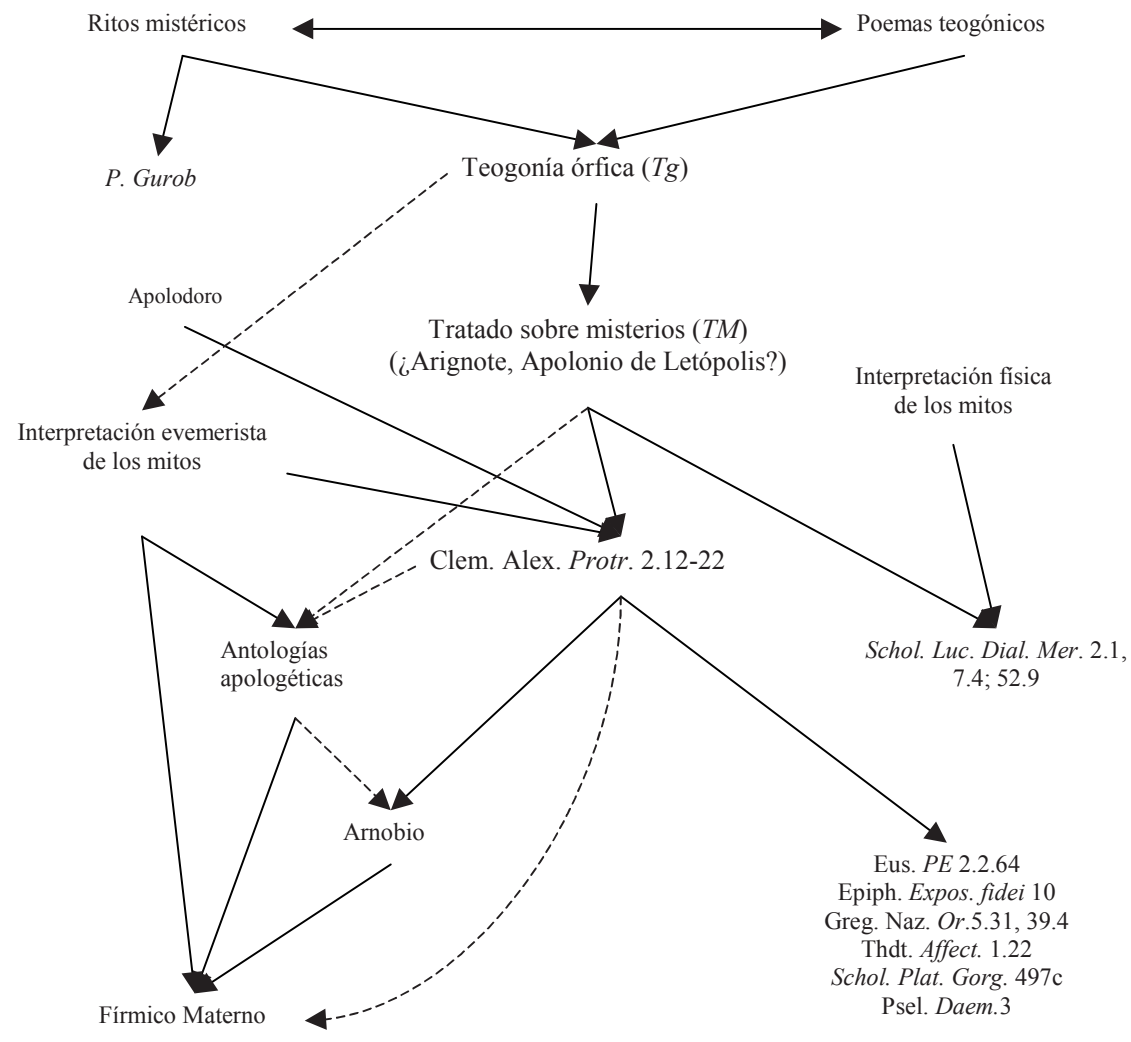

(He señalado con línea discontinua las que considero relaciones probables pero no seguras).

Con arreglo a las normas editoriales vigentes para las publicaciones periódicas del CSIC, se hace constar que el original definitivo de este artículo se recibió en la redacción de EMERITA en el primer semestre de 2006, tras haber sido aprobada su publicación en ese mismo período (25.06.06 - 15.05.06)

EMERITA (EM) LXXV 1, enero-junio $2007 \quad$ pp. 19-50 ISSN 0013-6662 